Research Article

\title{
Optimal Allocation Model of Virtual Power Plant Capacity considering Electric Vehicles
}

\author{
Shiping Geng, Caixia Tan (D, Dongxiao Niu, and Xiaopeng Guo
}

North China Electric Power University, Beijing 102206, China

Correspondence should be addressed to Caixia Tan; cx_sp@ncepu.edu.cn

Received 15 January 2021; Revised 28 May 2021; Accepted 3 June 2021; Published 14 June 2021

Academic Editor: Zhiyun Lin

Copyright $\odot 2021$ Shiping Geng et al. This is an open access article distributed under the Creative Commons Attribution License, which permits unrestricted use, distribution, and reproduction in any medium, provided the original work is properly cited.

To push forward the development of electric vehicles while improving the economy and environment of virtual power plants (VPPs), research on the optimization of VPP capacity considering electric vehicles is carried out. In this paper, based on this, this paper first analyzes the framework of the VPP with electric vehicles and models each unit of the VPP. Secondly, the typical scenarios of wind power, photovoltaic, electric vehicle charging and discharging, and load are formed by the Monte Carlo method to reduce the output deviation of each unit. Then, taking the maximization of the net income and clean energy consumption of the VPP as the objective function, the capacity optimal allocation model of the VPP considering multiobjective is constructed, and the conditional value-at-risk $(\mathrm{CVaR})$ is introduced to represent the investment uncertainty faced by the VPP. Finally, a VPP in a certain area of Shanxi Province is used to analyze a calculation example and solve it with CPLEX. The results of the calculation example show that, on the one hand, reasonable selection of the optimal scale of EV connected to the VPP is able to improve the economy and environment of the VPP. On the other hand, the introduction of CVaR is available for the improvement of the scientific nature of VPP capacity allocation decisions.

\section{Introduction}

Though electric vehicles enjoy a rapid development with the support of national policies, they are confronted with the challenges, such as the increase of the peak-valley difference of the system and the decrease of power quality due to their characteristics of centralized charging [1]. The virtual power plant integrates distributed energy, energy storage systems, and controllable loads with refined control and demand response methods, which can effectively solve the problems brought by the centralized charging of electric vehicles. Therefore, at present, reasonable planning and utilization of virtual power plant have become the focus of research in this field $[2,3]$.

In planning of a virtual power plant, the rational allocation of distributed energy units, conventional energy units, and energy storage systems forms the basis for the coordination of investment and income. In terms of capacity configuration, Chen et al. $[4,5]$ used game theory to study the capacity planning schemes of various distributed power sources. Li et al. [6] constructed a model of random optimal allocation of microgrid power capacity by generating a confrontation network to simulate a large number of scenes of wind and solar output and using K-medoids clustering to reduce the scenes. Xue et al. [7] used the Latin hypercube scene generation method and scene reduction technology to generate random scenes and combined robust optimization to modify the microgrid configuration scheme. In addition to the configuration of distributed power sources and microgrids, there are also works of the literature on the capacity configuration of integrated energy systems. Zhang et al. [8] proposed a planning model of IES electric-gas combined operation to determine the optimal switching time and capacity configuration of generator sets, electricto-gas, gas boilers, and other equipment. Zhang et al. [8,9] used the improved k-means algorithm and Monte Carlo algorithm to reduce wind power scenarios and built a comprehensive energy system capacity configuration model with the minimum total system cost as the objective function. Regarding the annualized cost of the system as the 
objective function and taking into consideration the electric energy interaction between multiple networks, Lin et al. $[10,11]$ optimized the selection and capacity of system equipment. Based on the single-tier optimal configuration, some works of the literature have constructed a double-layer optimal configuration model of the system. Considering the uncertainty of wind and solar, Yao et al. $[12,13]$ constructed a double-layer collaborative optimization configuration model. The upper layer is used to determine the equipment selection with the lowest annualized total cost, while the lower layer is utilized to determine the equipment capacity with the highest annual average utilization rate of the equipment, thereby realizing simultaneous optimization of system economy and utilization efficiency. Xiao et al. [14] constructed a two-stage capacity allocation model considering the planning and operation of the integrated energy system. The first stage achieves the lowest economic cost, and the second stage designs the optimal operation plan. Taking into account the uncertainty of demand response, Liu et al. [15-17] constructed a double-layer capacity optimal allocation model. Fan et al. [18] proposed a two-tier optimal configuration model for the multiregion integrated energy system. From the perspective of capacity allocation subjects, most of the existing researches focus on the distributed energy and integrated energy systems, but there are few studies on the capacity allocation of VPP. In terms of uncertainty analysis of capacity allocation, existing research studies mainly analyze the uncertainty of wind power, photovoltaics, and demand response, but there is no literature on the impact of the uncertainty of electric vehicle charging on the capacity allocation results. On the other hand, no attention was paid to the income uncertainty faced by the investors. For capacity allocation goals, though environmental protection goals need to be fully considered in the context of today's carbon neutrality and environmental protection, existing research studies mainly consider the economy.

Given the uncertainty of income faced by the investors, many methods are commonly used, including the value-at-risk (VaR) method [19], the profit variance method [20], and the conditional value-at-risk method $(\mathrm{CVaR})$ [21]. Among them, CVaR presents the conditional value-at-risk, and the average loss of the portfolio, reflecting the "tail risk" related to $\mathrm{VaR}$, is often used in systematic risk management. Shi et al. [22] introduced the CVaR method to optimize the heat storage and power storage capacity of the multienergy complementary system. Zheng et al. [23] used CVaR to characterize the severity of economic risks and verified that it is reasonable to use this method with an example. Guo et al. [24] applied $\mathrm{CVaR}$ to the optimal dispatch of microgrids in the spot market to reflect the uncertainty of real-time electricity prices. Wang et al. $[25,26]$ utilized CVaR to deal with the uncertainty of wind power output and established the optimal dispatch model of the power system while taking $\mathrm{CVaR}$ into account the integrated energy system. Yang et al. [27, 28] equivalently converted the difficult part of $\mathrm{VaR}$ in CVaR into a relatively simple function and used Monte Carlo and other sampling simulation methods to convert $\mathrm{CVaR}$ into linear programming, thereby reducing the difficulty of solving. Wei et al. [29] used CVaR as an indicator of risk measurement based on which the influence of risk preference on the power capacity configuration of virtual power plants was analyzed. Wang et al. $[30,31]$ used CVaR theory to measure the risk of system uncertainty to the scheduling in the virtual power plant scheduling process, thereby constraining the uncertainty risk to obtain the maximum benefit of the virtual power plant under acceptable conditions. The existing literature studies show that $\mathrm{CVaR}$ can effectively characterize economic risks. In order to further analyze the necessity of this study, this study is compared with other studies, as shown in Table 1.

Compared with existing research studies, this paper constructs a virtual power plant capacity optimization configuration model that takes into account electric vehicles. The innovations are as follows:

(1) Innovatively propose a capacity allocation model of virtual power plant that takes into account electric vehicles; on the one hand, it fills the gaps in the research of virtual power plant capacity configuration. On the other hand, it generates a set of typical scenarios and determines the optimal scale of electric vehicle access to VPP considering the uncertainty of electric vehicle charging load, thus enriching the research subject of capacity allocation, and pushing forward the development of electric vehicles.

(2) Innovatively propose to maximize the net income of VPP and clean energy consumption, thereby achieving the multiobjective capacity allocation. At the same time, it takes into account the environmental protection and economy of the virtual power plant, reduces the emission of pollutants, and responds to the goal of achieving carbon neutrality as soon as possible.

(3) In addition to the consideration of wind power, photovoltaics, and load uncertainty, the innovative introduction of CVaR that can effectively quantify risk characterizes the uncertainty faced by virtual power plant investors and improves the scientificity of virtual power plant capacity allocation.

The rest of the paper is organized as follows: Section 2 designs a virtual power plant framework with electric vehicles, which is followed by the modeling of each unit in the virtual power plant. In Section 3, to maximize the net income of VPP and the consumption of clean energy, a multiobjective capacity optimization configuration model is established. Section 4 designs a multiobjective solution process. Section 5 takes Shanxi Province, China, featuring the rapid growth of electric vehicles, as an example to conduct empirical analysis, thus verifying the validity of the model.

1.1. Nomenclature. The summary of parameters and variables is shown in Table 2. 
TABle 1: Comparison of research results.

\begin{tabular}{|c|c|c|c|}
\hline $\begin{array}{l}\text { Aspects of } \\
\text { comparison }\end{array}$ & Research situation of other papers & Research situation of this paper & Analysis of comparison \\
\hline $\begin{array}{l}\text { Research on electric } \\
\text { vehicle access to } \\
\text { virtual power plant }\end{array}$ & $\begin{array}{l}\text { Research on the optimal scheduling } \\
\text { strategy of the commercial virtual } \\
\text { power plant with electric vehicle } \\
\text { charging stations: the optimal } \\
\text { operation of the virtual power plant } \\
\text { is based on the optimization of the } \\
\text { economic benefits of the virtual } \\
\text { power plant. } \\
\text { Virtual power plants composed of } \\
\text { wind power and electric vehicles } \\
\text { participate in the multiagent game of } \\
\text { the market: this paper studies the } \\
\text { multiagent bidding optimization of } \\
\text { virtual power plants composed of } \\
\text { wind power companies and electric } \\
\text { vehicles in the mode of cooperation } \\
\text { and joint venture to participate in } \\
\text { the power market. } \\
\text { Collaborative optimization control } \\
\text { strategy of electric vehicle and } \\
\text { temperature control load virtual } \\
\text { power plant: the collaborative }\end{array}$ & $\begin{array}{l}\text { In this paper, the economic and } \\
\text { environmental protection of virtual } \\
\text { power plant are considered at the } \\
\text { same time, and the net income } \\
\text { maximization and the highest clean } \\
\text { energy consumption rate are taken as } \\
\text { multiobjective to configure each unit } \\
\text { of virtual power plant. }\end{array}$ & $\begin{array}{l}\text { Through the study of this paper and } \\
\text { other paper, we can find that (1) other } \\
\text { papers mainly focus on the optimal } \\
\text { scheduling of electric vehicles } \\
\text { connected to the virtual power plant } \\
\text { and participating in market bidding, } \\
\text { while this paper focuses on the } \\
\text { optimal configuration of electric } \\
\text { vehicles connected to the virtual } \\
\text { power plant. (2) most papers only } \\
\text { consider the economy of virtual } \\
\text { power plant, but in the case of } \\
\text { increasingly serious environmental } \\
\text { pollution, the environmental } \\
\text { protection of virtual power plant also } \\
\text { needs to be considered. }\end{array}$ \\
\hline
\end{tabular}
optimization control strategy of electric vehicle and temperature control load is constructed with the goal of minimum economic control cost.

Research on Literature 8, 15, 16, 17, 18, and 19: the integrated energy system as the main body of optimal allocation. capacity allocation
This paper focuses on the optimal configuration of electric vehicles connected to virtual power plant.
Through comparative analysis, it is concluded that the existing research focuses on the optimal allocation of the integrated energy system, but does not involve electric vehicles, and does not quantitatively analyze the impact of the scale of electric vehicles on a certain system.

\section{This paper not only analyzes the} uncertainty of the source end and Literature 6, 7, and 25: the Research aspects of uncertainty in systems uncertainty of electricity price in wind power, photovoltaic, and market is studied. end of the virtual power plant uncertainty research, the uncertainty but also considers the uncertainty of of investment of virtual power plant the investment decision of the virtual investors is increased. power plant investors.

\section{Framework and Unit Modeling of VPP with EV}

2.1. Framework of VPP with EVs. In addition to renewable energy, such as wind power and photovoltaics, VPP can also gather resources, such as EVs and user-side controllable loads. However, there are uncertainties in the controllable load of renewable energy, EVs, and users. To maintain the balance between supply and demand, thermal generators, energy storage systems, and other equipment are installed in the VPP to reduce the uncertainty, with the specific framework of the VPP shown in Figure 1.

Taking a day of a year in a virtual power plant as an example, the wind power generation, photovoltaic power generation, thermal power generation, electric vehicle charging, and discharging and load are predicted at 7:00 on the day before the actual operation. Compare the output and load at 7 : 30. When the output is greater than the load demand, judge whether the multimargin exceeds the maximum energy storage of the energy storage system at 8:00 before the day-ahead market starts (assuming that the day-ahead market starts at 9: 30). If the answer is positive, the energy is first stored in the energy storage system to its maximum extent, and the remaining energy is then sold to the grid at a price lower than the current market price; otherwise, the surplus is stored in the energy storage system. When the output is less than the load demand, judgement on whether the shortfall exceeds the maximum discharge energy of the energy storage system will be initiated. If the answer is positive, the energy storage system will discharge energy first, and the remaining shortfall will be 
TABLE 2: Summary of parameters and variables.

\begin{tabular}{|c|c|c|c|}
\hline \multicolumn{4}{|c|}{ Parameter } \\
\hline$P_{w p p, e}^{j}$ & The output of the $j$-th wind turbine at time $t, \mathrm{~kW}$ & $v_{. t}$ & Wind speed at time $t, \mathrm{~m} / \mathrm{s}$ \\
\hline & Cut-in wind speed of the $j$-th wind turbine, $\mathrm{m} / \mathrm{s}$ & $v_{\text {out }}^{j^{t}}$ & Cut-out wind speed of the $j$-th wind turbine, $\mathrm{m} / \mathrm{s}$ \\
\hline$v_{w p p, e}^{J}$ & Rated wind speed of the $j$-th wind turbine, $\mathrm{m} / \mathrm{s}$ & $\lambda_{p v}^{j}$ & Photoelectric conversion efficiency, \% \\
\hline$S_{p^{v}}^{j}$ & The area of photovoltaic panels, $\mathrm{m}^{2}$ & $E_{t}^{p v}$ & Light intensity, $\mathrm{W} / \mathrm{m}^{2}$ \\
\hline & Conversion efficiency of thermal power generating units, \% & $\partial_{T l, t}$ & Transferable load Boolean variable \\
\hline$P_{\text {load }, t}$ & Original load, kW & $\mu_{D_{k}}$ & Average travel distance of category $k$ electric vehicles \\
\hline$\sigma_{D_{k}}$ & Standard deviation distance of category $k$ electric vehicles & $S O C_{\min }^{k}$ & The minimum state of charge of electric vehicles \\
\hline $\bar{C}_{\text {Inv }, w}$ & Unit investment and construction cost of wind turbine, \$ & $\bar{C}_{\text {Inv, pv }}$ & $\begin{array}{l}\text { Unit investment and construction cost of photovoltaic } \\
\text { panels, } \$\end{array}$ \\
\hline $\bar{C}_{\text {Inv }, D G}$ & $\begin{array}{l}\text { Unit investment and construction cost of thermal power } \\
\text { generating unit, } \$\end{array}$ & $\bar{C}_{\text {Inv }, q E V}$ & $\begin{array}{c}\text { Investment and construction cost of unit fast charge } \\
\text { charging pile, } \$\end{array}$ \\
\hline $\bar{C}_{\text {Inv }, s E V}$ & $\begin{array}{c}\text { Investment and construction cost of unit slow charge } \\
\text { charging pile, } \$\end{array}$ & $\bar{C}_{\text {Inv,ESS }}$ & $\begin{array}{l}\text { Investment and construction cost of unit energy storage } \\
\text { system, } \$\end{array}$ \\
\hline$\eta_{w p p, t}$ & Operation and maintenance rate of wind turbine, $\%$ & $\eta_{p v, t}$ & $\begin{array}{l}\text { Operation and maintenance rate of photovoltaic panels, } \\
\qquad \%\end{array}$ \\
\hline$\eta_{q E V, t}$ & Operation and maintenance rate of fast-charging pile, \% & $\eta_{s E V, t}$ & Operation and maintenance rate of slow-charging pile, $\%$ \\
\hline$\eta_{D G, t}$ & $\begin{array}{c}\text { Operation and maintenance rate of thermal power } \\
\text { generating units, } \%\end{array}$ & $\bar{C}_{o p, w}$ & Operation and maintenance rate of wind turbine, $\$$ \\
\hline $\bar{C}_{o p, p v}$ & Operation and maintenance rate of photovoltaic panels, $\$$ & $\bar{C}_{q E V, w}$ & Operation and maintenance rate of fast-charging pile, $\$$ \\
\hline $\bar{C}_{o p, s E V}$ & Operation and maintenance rate of slow-charging pile, $\$$ & $\bar{C}_{o p, D G}$ & $\begin{array}{c}\text { Operation and maintenance rate of thermal power } \\
\text { generating units, } \$\end{array}$ \\
\hline $\bar{C}_{r l}$ & Unit interruptible load compensation cost, $\$ / \mathrm{kW}$ & $\bar{C}_{T l}$ & Unit transferable load compensation cost, $\$ / \mathrm{kW}$ \\
\hline \multicolumn{4}{|c|}{ Variable } \\
\hline$N_{w}^{\mathrm{wpetr}}$ & Number of wind turbines in scenario wpetr & $N_{D G}^{\text {wpetr }}$ & Number of thermal power generating in scenario wpetr \\
\hline$N_{p v}^{\text {wpetr }}$ & Number of photovoltaic panels in scenario wpetr & $N_{E S S}^{\text {wpetr }}$ & Number of energy storage systems in scenario wpetr \\
\hline$N_{q E V}^{\text {wpetr }}$ & Number of fast-charging piles in scenario wpetr & $N_{s E V}^{\text {wpetr }}$ & Number of slow-charging piles in scenario wpetr \\
\hline$P_{w p p, t}^{j}$ & The output of the $j$-th wind turbine at time $t, \mathrm{~kW}$ & $P_{p v, t}^{j}$ & The output of photovoltaic panels at time $t, \mathrm{~kW}$ \\
\hline$P_{q E V, t}^{j}$ & Fast-charging load of the $j$-th electric vehicle at time $t, \mathrm{~kW}$ & $P_{s E V, t}^{j}$ & $\begin{array}{l}\text { Slow-charging load of the } j \text {-th electric vehicle at time } t \text {, } \\
\qquad \mathrm{kW}\end{array}$ \\
\hline$P_{D G, t}^{j}$ & $\begin{array}{l}\text { The output of the } j \text {-th thermal power generating unit at time } \\
\qquad t, \mathrm{~kW}\end{array}$ & $P_{E S S, t}^{d i s, w p e t r}$ & $\begin{array}{l}\text { Energy storage system discharge power at time } t \text { in } \\
\text { scenario wpetr; } \mathrm{kW}\end{array}$ \\
\hline$P_{\text {grid,b,t }}^{\text {wpetr }}$ & Purchase electricity from the grid at time $t, \mathrm{~kW}$ & $P_{E S S, t}^{c h a, \text { wpetr }}$ & $\begin{array}{c}\text { Energy storage system charge power at time } t \text { in scenario } \\
\text { wpetr, } \mathrm{kW}\end{array}$ \\
\hline$P_{\text {grid }, s, t}^{\text {wpetr }}$ & Sell electricity from the grid at time $t, \mathrm{~kW}$ & & \\
\hline \multicolumn{4}{|c|}{ Acronyms } \\
\hline CVaR & Conditional value-at-risk & $\mathrm{VaR}$ & \\
\hline VPP & Virtual power plant & $\mathrm{EV}$ & Electric vehicle \\
\hline
\end{tabular}

purchased from the grid at a price higher than the previous market price; otherwise, the shortfall energy is discharged by the energy storage system.

Among them, the bidding process of the VPP in the dayahead market is shown in Figure 2.

It can be seen from Figure 2 that the Market Control Center announced the bidding information before $9: 30$ on the bidding day. From 9:30 to 10:00, power is submitted by each wind power, photovoltaic power generating unit, and thermal power generating unit. In the meantime, the user submits the load demand, and the VPP operator submits the declaration to the control center based on the output and load. At 10:30 on the bidding day, the day-ahead market clearing will be carried out to form the day-ahead market-clearing price. Besides, the real-time clearing is carried out in 15 minutes within the operating day.

\subsection{Unit Modeling of VPP with EV}

(1) Wind turbine: the output of the wind turbine generator mainly depends on the wind speed. Specifically, when the wind speed is less than the cut-in wind speed, or greater than the cut-out wind speed, the output of the wind turbine is 0 , while in the case that the wind speed is between the cut-in wind speed and the rated wind speed, the output of the wind turbine generator is positively related to the wind speed. The specific output is shown in the following equation [32]:

$$
P_{w p p, t}^{j}= \begin{cases}0, & 0 \leq v_{t}<v_{i n}^{j}, v_{t}>v_{\text {out }}^{j}, \\ \frac{v_{t}-v_{\text {in }}^{j}}{v_{\text {out }}^{j}-v_{\text {in }}^{j}} \cdot P_{w p p, e}^{j}, & v_{\text {in }}^{j} \leq v_{t} \leq v_{w p p, e}^{j}, \\ P_{w p p, e}^{j}, & v_{w p p, e}^{j}<v_{t} \leq v_{\text {out }}^{j},\end{cases}
$$

where $P_{w p p, t}^{j}$ refers to the output of the $j$-th wind turbine at time $t ; P_{w p p, e}^{j}$ represents the rated output 


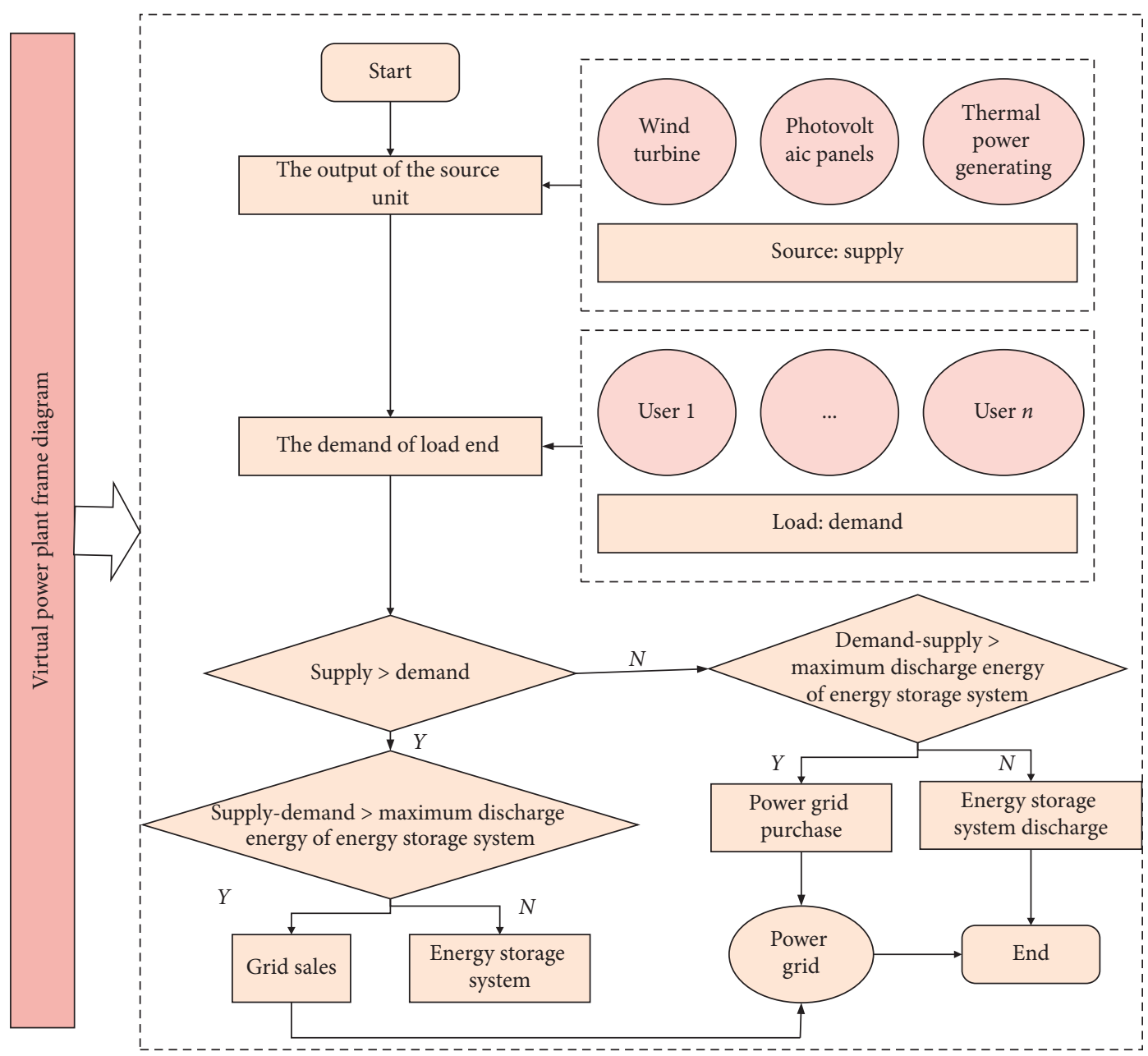

Figure 1: Framework of VPP.
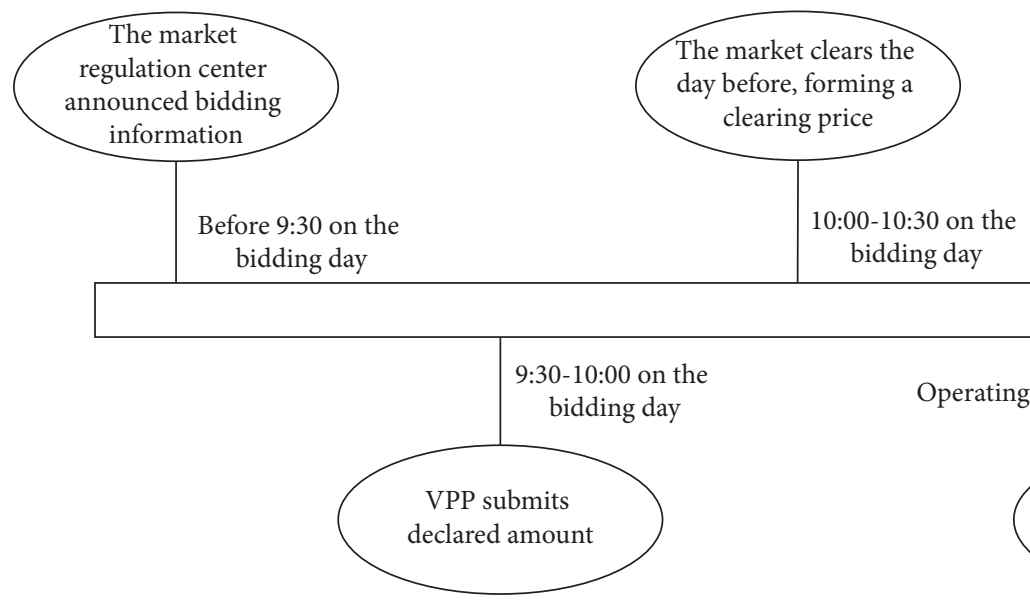

FIgUre 2: Process of the VPP in the day-ahead market.

of the $j$-th wind turbine; $v_{t}$ denotes the wind speed at time $t$; and $v_{i n}^{j}, v_{\text {out }}^{j}$ and $v_{w p p, e}^{j}$ are the cut-in wind speed, cut-out wind speed, and rated wind speed of the $j$-th wind turbine, respectively.
(2) Photovoltaic panels: the output of the photovoltaic panel depends on the light intensity and the area of the photovoltaic panel, as shown in the following equation [33]: 


$$
P_{p v, t}^{j}=\lambda_{p v}^{j} \cdot S_{p v}^{j} \cdot E_{t},
$$

where $P_{p v, t}^{j}$ refers to the output of the photovoltaic panel at time $t ; \lambda_{p v}^{j}$ represents the photoelectric conversion efficiency; $S_{p v}^{j}$ denotes the area of the photovoltaic panel, and $E_{t}$ is the light intensity.

(3) Thermal power generating set: the output of thermal power generators depends on the amount of coal burned and the conversion efficiency, as shown in the following equation:

$$
P_{D G, t}^{j}=\lambda_{D G}^{j} \cdot m_{D G, t},
$$

where $P_{D G, t}^{j}$ refers to the output of the $j$-th thermal power generating unit at time $t ; \lambda_{D G}^{j}$ represents the conversion efficiency of the $j$-th thermal power generating unit; and $m_{D G, t}$ denotes the amount of coal burned by the thermal power generating unit at time $t$.

(4) Controllable load: controllable load is also called a flexible load, which includes the transferable load and the interruptible load. Among them, the transferable load depends on the transferred load and the load transferred from the rest of the time; the interrupted load depends on the ratio of the interrupted load, as shown in the following equations, respectively:

$$
\begin{aligned}
& P_{T l, t}=\partial_{T l, t} \cdot P_{\text {load }, t} \cdot \lambda_{T l, t}-\sum_{i \notin t}\left(\partial_{T l, i} \cdot P_{\text {load }, i} \cdot \lambda_{T l, i}\right), \\
& P_{r l, t}=P_{\text {load }, t} \cdot \lambda_{r l, t},
\end{aligned}
$$

where $P_{T l, t}$ refers to the transfer load at time $t ; \partial_{T l, t}$ represents a Boolean variable, which indicates whether the load is transferable or not during $t$; in the case that the load can be transferred in the period of $t, \partial_{T l, t}=1$, otherwise, $\partial_{T l, t}=0 ; P_{\text {load }, t}$ represents the load before the transfer of the load, and the load is not reduced at time $t ; \lambda_{T l, t}$ denotes the transfer ratio at time $t ; P_{r l, t}$ is the load reduction at time $t$; and $\lambda_{r l, t}$ refers to the reduction ratio at time $t$.

(5) EV charging load: after considering the access of electric vehicles to the virtual power plant, the charging and discharging of electric vehicles are random and subjective, which aggravates the overall uncertainty of the virtual power plant. Therefore, the accurate analysis of electric vehicle charge and discharge load is the key.

EVs mainly include taxis, private cars, and electric buses. Among them, taxis and electric buses cannot be charged for a long time due to their operating hours; therefore, fast charging is mainly used. In contrast, private cars are mainly used for driving from home-workplace-home, which makes the long charging time acceptable; in that case, slow charging is mainly adopted. The selection of the charging strategy for $\mathrm{EV}$ in each period is related to the EV's state of change which is closely related to the EV's driving distance. The mileage of
EVs obeys a normal distribution, as shown in the following equation [34]:

$$
D\left(x_{k}\right)=\frac{1}{\sqrt{2 \pi} \sigma_{D_{k}}} e^{-\left(\left(\left[\operatorname{In} D\left(x_{k}\right)-\mu_{D_{k}}\right]^{2}\right) / 2 \sigma_{D_{k}}^{2}\right)},
$$

where $\mu_{D_{k}}$ and $\sigma_{D_{k}}$ refer to the mean and standard deviation of mileage, respectively.

Since the state of charge of an electric vehicle at every moment is constrained by the minimum state of charge, that is, when the electric vehicle is not charged at time $t$, the charge value at time $t$ minus the power consumption at time $t+1$ still needs to meet the minimum state of charge. Combining mileage accordingly, the EV's state of charge is judged by equation (7). If equation (7) is satisfied, the EV does not need to be charged at time $t$; otherwise, the EV is charged [35]:

$$
\left\{\begin{array}{l}
\operatorname{SOC}_{t, k}-\frac{D_{t+1, k} \cdot \bar{g}_{k}}{C_{k}} \geq \mathrm{SOC}_{\mathrm{min}} \\
\mathrm{SOC}_{t, k}=\mathrm{SOC}_{t-1, k}-\frac{D_{t-1, k} \cdot \bar{g}_{k}}{C_{k}}
\end{array}\right.
$$

where $\mathrm{SOC}_{t, k}$ refers to the $k$-th EV's state of charge at time $t$; $\bar{g}_{k}$ represents the power consumption of the $k$-th EV per kilometer; $C_{k}$ denotes the $k^{\text {th }} \mathrm{EV}$ capacity; and $\mathrm{SOC}_{\min }$ is the minimum value of the EV's state of charge; $D_{t+1, k}$ and $D_{t-1, k}$ are the mileage of the $k$-th electric vehicle at time $t+1$ and $t-1$, respectively.

According to the EV's state of charge, the charging time of the EV is calculated based on

$$
t_{k}= \begin{cases}0, & \mathrm{SOC}_{t, k}-\frac{D_{t+1, k} \cdot \bar{g}_{k}}{C_{k}}>\mathrm{SOC}_{\text {min }}, \\ \frac{\left(\mathrm{SOC}_{\max }-\mathrm{SOC}_{t, k}\right) \cdot C_{k}}{\lambda_{E V, k} P_{E V, k, t}}, & t_{s, k} \geq t_{E V, k}, \\ t_{s, k}, & t_{s, k}<t_{E V, k},\end{cases}
$$

where $t_{k}$ refers to the charging time of the $\mathrm{EV} ; t_{s, k}$ represents the parking time of the $k^{\mathrm{th}} \mathrm{EV}$, and $t_{E V, k}$ denotes the charging time of the EV; $P_{E V, k, t}$ is the charging power of the $k^{\text {th }}$ electric vehicle at time $t$ :

$$
\mathrm{SOC}_{t+1}= \begin{cases}\operatorname{SOC}_{t}, & \mathrm{SOC}_{t, k}-\frac{D_{t+1, k} \cdot \bar{g}_{k}}{C_{k}}>\mathrm{SOC}_{\min }, \\ \operatorname{SOC}_{\text {max }}, & t_{s, k} \geq t_{E V, k}, \\ \operatorname{SOC}_{t}+t_{k} \frac{\lambda_{E V, k} P_{E V, k, t}}{C_{k}}, & t_{s, k}<t_{E V, k} .\end{cases}
$$

By continuously updating the EVs' state of charge, the cumulative charging load of EVs $P_{E V, t}$ can be obtained. $P_{E V, t}$ is the accumulation of the charging power $P_{E V, k, t}$ at time $t$ of 
three types of electric vehicles: taxis, private cars, and electric buses, as shown in

$$
\left\{\begin{array}{l}
P_{E V, t}=\sum_{k=1}^{3} P_{E V, k, t}, \\
P_{E V, k, t}=\frac{\left(\mathrm{SOC}_{\max }-\mathrm{SOC}_{t, k}\right) \cdot C_{k}}{\lambda_{E V, k}},
\end{array}\right.
$$

where $P_{E V, t}$ refers to the cumulative charging load of EVs; $k=1,2,3$ represents taxis, private cars, and electric buses, respectively.

\section{Capacity Optimal Allocation Model of VPP considering Multiple Objectives}

The investment and construction model of VPP is the BOT model, namely, build operation transfer. The VPP service provider shall invest in construction and operation, and after the operation expires, the VPP service provider will transfer the VPP to the government.

Because wind power generation, photovoltaic power generation, controllable load, and electric vehicles all have uncertainty and randomness, they are a random problem. In the process of solving, the random problem needs to be transformed into a deterministic problem. The Monte Carlo method is used to form the output scenario set of wind power generation, photovoltaic power generation, electric vehicle charging load, interruptible load, and reducible load. Due to the space limitation, the Monte Carlo method is no longer described, mainly in reference [36]. $s$ $w=\left\{w_{i}, i=1,2, \ldots, n_{w}\right\}, \quad p=\left\{p_{j}, j=1,2, \ldots, n_{p v}\right\}$, $e=\left\{e_{k}, k=1,2, \ldots, n_{E V}\right\}, \quad t=\left\{t_{m}, m=1,2, \ldots, n_{T l}\right\}$, and $r=\left\{r_{s}, s=1,2, \ldots, n_{r l}\right\}$ are considered to reduce the load. The total number of scenes is $n_{\text {total }}=n_{w} \cdot n_{p v} \cdot n_{E V} \cdot n_{T l} \cdot n_{r l}$.
And the probability of each scene is $\theta\left(w_{i}\right), \theta\left(P_{j}\right)$, $\theta\left(e_{k}\right) \theta\left(t_{m}\right)$, and $\theta\left(r_{s}\right)$, respectively.

3.1. Objective Function. EV may have a certain impact on the load curve by its charging load when connecting to a VPP. From the economic point of view, the goal of the VPP is to maximize the net income; while for social benefit, the VPP also pursues the largest consumption of clean energy; therefore, it is necessary to construct a VPP capacity optimization configuration model that considers multiple objectives.

3.1.1. Maximize Net Income. The net income of the VPP is the difference between the total system revenue and the total system cost. At the same time, wpetr is used to represent the values of variables in scenes $w_{i}, p_{j}, e_{k}, t_{m}$, and $r_{s}$, respectively, as shown in

$$
\begin{aligned}
R_{\text {net }}= & R_{\text {sale }}^{\mathrm{wpetr}}-C_{\text {Inv }}^{\mathrm{wpetr}}-C_{o p}^{\mathrm{wpetr}}-C_{g e}^{\mathrm{wpetr}}-C_{r l}^{\mathrm{wpetr}} \\
& -C_{T l}^{\mathrm{wpetr}}-C_{\mathrm{env}}^{\mathrm{wpetr}}-C_{B}^{\mathrm{wpetr}}-C_{\mathrm{ESS}}^{\mathrm{wpetr}}
\end{aligned}
$$

where $R_{n e t}$ refers to the net income of the VPP; $R_{\text {sale }}^{\text {wpetr }}$ represents the total revenue of VPP sales; $C_{\text {Inv }}^{\text {wpetr }}, C_{o p}^{\text {wpetr }}$, $C_{g e}^{\text {wpetr }}, C_{r l}^{\text {wpetr }}, C_{T l}^{\text {wpetr }}, C_{\text {env }}^{\text {wpetr }}, C_{B}^{\text {wpetr }}$, and $C_{\text {ESS }}^{\text {wpetr }}$ are VPP investment and construction cost, operation and maintenance cost, thermal power generation cost, interruptible load compensation cost, transferable load cost, environmental cost, power purchase cost from the grid, and energy storage system cost, respectively:

(1) Investment and construction cost

Investment and construction costs mainly refer to the costs incurred in purchasing and installing each unit:

$$
\begin{aligned}
C_{\text {Inv }}^{\mathrm{wpetr}}= & \left(N_{w}^{\mathrm{wpetr}} \cdot \bar{C}_{\mathrm{Inv}, w}+N_{p v}^{\mathrm{wpetr}} \cdot \bar{C}_{\mathrm{Inv}, p v}+N_{q E V}^{\mathrm{wpetr}} \cdot \bar{C}_{\mathrm{Inv}, q E V}+N_{s E V}^{\mathrm{wpetr}} \cdot \bar{C}_{\mathrm{Inv}, s E V}+N_{D G}^{\mathrm{wpetr}} \cdot \bar{C}_{\mathrm{Inv}, D G}+N_{\mathrm{ESS}}^{\mathrm{wpetr}} \cdot \bar{C}_{\mathrm{Inv}, \mathrm{ESS}}\right) \\
& \cdot \frac{r(1+r)^{T}}{(1+r)^{T}-1},
\end{aligned}
$$

where $N_{w}^{\text {wpetr }}, N_{D G}^{\text {wpetr }}$, and $N_{\text {ESS }}^{\text {wpetr }}$ refer to the number of wind turbines, thermal generators, and energy storage systems, respectively; $N_{p v}^{\text {wpetr }}$ represents the number of photovoltaic panels; $N_{q E V}^{\text {wpetr }}$ and $N_{s E V}^{\text {wpetr }}$ denote the number of fast-charging piles and slow-charging piles, respectively; $\bar{C}_{\text {Inv, } w}$, $\bar{C}_{\text {Inv }, p v}, \bar{C}_{\text {Inv }, D G}, \bar{C}_{\text {Inv }, q E V}, \bar{C}_{\text {Inv }, s E V}$, and $\bar{C}_{\text {Inv,ESS }}$ are the unit investment and construction costs of unit wind turbines, photovoltaic panels, thermal power generators, fast-charging piles, slow-charging piles, and energy storage systems, respectively; $r$ is the discount rate; and $T$ refers to the operating life of the system.

(2) Annual operation and maintenance cost

The annual operation and maintenance cost depends on the output of each unit and the operation and maintenance rate, as shown in 


$$
\begin{aligned}
C_{o p}^{w p e t r}= & \sum_{t=1}^{8760}\left(\sum_{j=1}^{N_{w}^{w p e t r}} P_{w p p, t}^{j} \cdot \eta_{w p p, t} \cdot \bar{C}_{o p, w}+\sum_{j=1}^{N_{p v}^{\text {wpetr }}} P_{p v, t}^{j} \cdot \eta_{p v, t} \cdot \bar{C}_{o p, p v}+\sum_{j=1}^{N_{q E V}^{\text {wpetr }}} P_{q E V, t}^{j} \cdot \eta_{q E V, t} \cdot \bar{C}_{q E V, w}\right. \\
& \left.+\sum_{j=1}^{N_{s E V}^{\text {wpetr }}} P_{s E V, t}^{j} \cdot \eta_{s E V, t} \cdot \bar{C}_{o p, s E V}+\sum_{j=1}^{N_{D G}^{\text {wpetr }}} P_{D G, t}^{j} \cdot \eta_{D G, t} \cdot \bar{C}_{o p, D G}\right),
\end{aligned}
$$

where $\eta_{w p p, t}, \eta_{p v, t}, \eta_{q E V, t}, \eta_{s E V, t}$, and $\eta_{D G, t}$ refer to the operation and maintenance rates of wind turbines, photovoltaic panels, fast-charging piles, slowcharging piles, and thermal generating sets, respectively; $\bar{C}_{o p, w}, \bar{C}_{o p, p v}, \bar{C}_{q E V, w}, \bar{C}_{o p, s E V}$, and $\bar{C}_{o p, D G}$ represent the unit operation and maintenance costs of wind turbines, photovoltaic panels, fast-charging piles, slow-charging piles, and thermal generating sets, respectively.

(3) Thermal power cost

$C_{g e}^{\mathrm{wpetr}}=\sum_{t=1}^{8760}\left[a\left(\sum_{j=1}^{N_{G D}^{\mathrm{wpetr}}} P_{D G, t}^{j}\right)^{2}+b \sum_{j=1}^{N_{G D}^{\mathrm{wpetr}}} P_{D G, t}^{j}+c\right]$,

where $a, b$, and $c$ refer to the power generation cost coefficients.

(4) Interruptible load compensation cost

$$
C_{r l}^{\mathrm{wpetr}}=\sum_{t=1}^{8760} P_{r l, t} \cdot \bar{C}_{r l}
$$

where $\bar{C}_{r l}$ refers to the unit interruptible load compensation cost.
(5) Transferable load cost

$$
C_{T l}^{\mathrm{wpetr}}=\sum_{t=1}^{8760} P_{T l, t} \cdot \bar{C}_{T l},
$$

where $\bar{C}_{T l}$ represents the unit transferable load compensation cost.

(6) Environmental cost

$$
C_{e n v}^{\mathrm{wpetr}}=\sum_{t=1}^{8760} \sum_{e=1}^{n_{e}} H_{e}\left(F_{e}+v_{e}\right) P_{D G, t},
$$

where $n_{e}$ denotes the type of pollutant; $H_{e}$ refers to the total discharge of pollutants $e ; F_{e}$ denotes the fine's magnitude of the pollutant $e$; and $v_{e}$ is environmental value.

(7) Grid purchase cost

$$
C_{B}^{\mathrm{wpetr}}=\sum_{t=1}^{8760} P_{\text {grid }, b, t} \cdot P_{\text {grid }, b}
$$

where $p_{\text {grid, } b}$ refers to the unit price of electricity purchased from the grid.

(8) Energy storage system cost

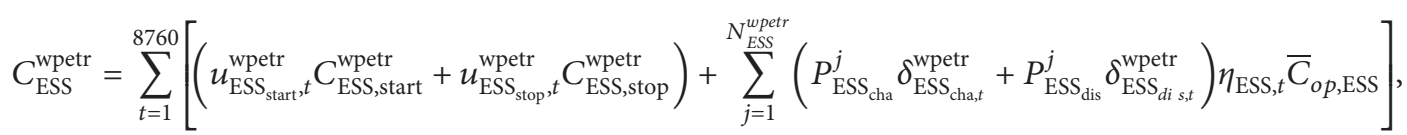

where $u_{\mathrm{ESS}_{\text {start }}, t}^{\text {wpetr }}$ is a Boolean variable, $u_{\mathrm{ESS}_{\text {start }}, t}^{\text {wpetr }}=1$ indicates that the energy storage system is started, and $u_{\mathrm{ESS}_{\text {start }}, t}^{\text {wpetr }}=0$ indicates that the energy storage system is not started; $C_{\mathrm{ESS} \text {,start }}^{\mathrm{wpetr}}$ and $C_{\mathrm{ESS} \text {,stop }}^{\text {wpetre the }}$ start and stop cost of energy storage system; $\delta_{\mathrm{ESS}}^{\mathrm{wpetr}}$ is also a Boolean variable, $\delta_{\mathrm{ESS}_{\mathrm{what}}}^{\mathrm{wpetr}}=1$ indicates that the energy storage system is charged, and $\delta_{\mathrm{ESS}_{\text {chat }}}^{\text {wpetr }}=0$ indicates that the energy storage system is not charged; $\eta_{\mathrm{ESS}, t}$ is the operation and maintenance rate of the energy storage system; $\bar{C}_{o p \text {,Ess }}$ is the unit operation and maintenance cost of the energy storage system.

(9) Electricity sales revenue: the electricity sales revenue of the VPP includes the charging fee paid by the EV owner, the energy usage fee paid by the general user, and the revenue obtained by selling electric energy to the grid:

$$
R_{\mathrm{sale}}^{\mathrm{wpetr}}=\sum_{t=1}^{8760}\left[\left(P_{\mathrm{load}, t}-P_{T l, t}-P_{r l, t}\right) \cdot \bar{p}_{\mathrm{use}}+P_{\mathrm{grid}, s, t} \cdot p_{\mathrm{grid}, \mathrm{s}}+P_{E V, t} \cdot p_{E V}\right]
$$


where $\bar{p}_{\text {use }}$ refers to the user energy unit price; $p_{\text {grid,s }}$ represents the unit price of energy sold to the grid; and $p_{E V}$ denotes the charging price of EVs.

To effectively measure the uncertainty risk of wind turbines, photovoltaic panels, EV charging loads, and controllable loads, $\mathrm{CVaR}$ is introduced and multiplied by the investor's risk preference $B$ to represent the risk $r_{\text {risk }}$. The degree of investor's risk preference indicates the investor's attitude towards risk, and its value range is $B \geq 0$. When $B$ is smaller than 0.1, it means that investors are risk preference type. Investors want to exchange for higher returns with greater risks. When $B$ is larger than 0.5 , it means that investors are risk averse and their investment strategies are conservative. Investors should choose the risk preference coefficient according to their risk preference. As shown in

$$
r_{\text {risk }}=\left(\alpha+\frac{1}{1-\beta} \sum_{i=1}^{n_{w}} \theta\left(w_{i}\right) \sum_{j=1}^{n_{p v}} \theta\left(p_{j}\right) \sum_{k=1}^{n_{E V}} \theta\left(e_{k}\right) \sum_{k=1}^{n_{T l}} \theta\left(t_{m}\right) \sum_{k=1}^{n_{r l}} \theta\left(r_{s}\right)\right) \cdot B
$$

where $\alpha$ refers to the $\mathrm{VaR}$ value and $\beta$ represents the confidence coefficient.

Combined with the degree of risk, the objective function for maximizing net income can be obtained based on

$$
\max f_{1}=\max \left(R_{\text {net }}-r_{\text {risk }}\right) \text {. }
$$

3.1.2. Maximize Clean Energy Consumption. The consumption of clean energy is characterized by the ratio of clean energy output to the total output of the VPP (including the output of clean energy and the output of thermal power units), as shown in

$$
\max f_{2}=\max \frac{\sum_{j=1}^{N_{w}^{\text {wpetr }}} P_{w p p, t}^{j}+\sum_{j=1}^{N_{p p e t r}^{\text {wetr }}} P_{p v, t}^{j}}{\sum_{j=1}^{N_{w}^{\text {wpetr }}} P_{w p p, t}^{j}+\sum_{j=1}^{N_{p p e t r}^{\text {wetr }}} P_{p v, t}^{j}+\sum_{j=1}^{N_{\mathrm{G} p e t r}} P_{D G, t}^{j}} .
$$

3.2. Restrictions. The constraints of the multiobjective capacity optimization configuration model include unit output and climbing constraints, EV constraints, controllable load constraints, energy storage system constraints, grid interaction constraints, power balance constraints, and scenario probability constraints $[37,38]$.

(1) Unit output and climbing constraints: the output and climbing constraints of wind turbines, photovoltaic panels, and thermal generators are shown in equations (24) and (25), respectively:

$$
\begin{aligned}
& \left\{\begin{array}{l}
P_{w p p}^{\min } \leq P_{w p p, t}^{j} \leq P_{w p p}^{\max }, \\
P_{p v}^{\min } \leq P_{p v, t}^{j} \leq P_{p v}^{\max }, \\
P_{D G}^{\min } \leq P_{D G, t}^{j} \leq P_{D G}^{\max },
\end{array}\right. \\
& \left\{\begin{array}{l}
r_{w p p \text { down }}^{j} \leq P_{w p p, t}^{j}-P_{w p p, t-1}^{j} \leq r_{w p p, \text { up }}^{j} \\
r_{D G \text {,down }}^{j} \leq P_{D G, t}^{j}-P_{D G, t-1}^{j} \leq r_{D G, \text { up }}^{j}
\end{array}\right.
\end{aligned}
$$

where $P_{i}^{\min }$ and $P_{i}^{\max }$ refer to the minimum and maximum output of unit $i(i=w p p, p v, D G)$, and $r_{i, \text { down }}^{j}$ and $r_{i, u p}^{j}$ represent the minimum and maximum values of the climb of unit $i(i=w p p, D G)$, respectively.
(2) EV constraints: EV constraints include charging power constraints and capacity constraints, as shown in

$$
\left\{\begin{array}{l}
0 \leq P_{E V, k, t} \leq P_{E V, k}^{\max } \cdot \partial_{E V, k} \\
0 \leq C_{k, t} \leq C_{k}^{\max }
\end{array}\right.
$$

where $P_{E V, k}^{\max }$ refers to the maximum charging power of the $k$ th EV; $\partial_{E V, k}$ represents the Boolean variable of the $k$-th EV's charging state, and $\partial_{E V, k}=1$ means that the electric car is being charged; otherwise, it is not being charged. And $C_{k}^{\max }$ is the maximum capacity of the $k$-th $\mathrm{EV}$.

(3) Controllable load constraint: controllable load constraints include transferable load constraints and interruptible load constraints:

$$
\left\{\begin{array}{l}
0 \leq P_{T l, t} \leq P_{T l}^{\max } \\
0 \leq P_{r l, t} \leq P_{r l}^{\max }
\end{array}\right.
$$

where $P_{T l}^{\max }$ and $P_{r l}^{\max }$ refer to the maximum values of transferable load and interruptible load, respectively.

(4) Energy storage system constraints: energy storage system constraints include balance constraints and energy discharge limit constraints, as shown in

$$
\left\{\begin{array}{l}
Q_{\mathrm{ESS}, t}=Q_{\mathrm{ESS}, t-1}+\lambda_{\mathrm{ESS}, \mathrm{cha}} \cdot P_{\mathrm{ESS}, t}^{\text {cha,wpetr }}-\frac{P_{\mathrm{ESS}, t}^{\mathrm{dis}, \mathrm{w} e t r}}{\lambda_{\mathrm{ESS}, \mathrm{dis}}} \\
0 \leq Q_{\mathrm{ESS}, t} \leq Q_{\mathrm{ESS}}^{\max }, \\
0 \leq P_{\mathrm{ESS}, t}^{\text {cha,wpetr }} \leq P_{\mathrm{ESS}}^{\text {cha,max }} \partial_{\mathrm{ESS}, \text { cha }}, \\
0 \leq P_{\mathrm{ESS}, t}^{\mathrm{dis}, \mathrm{wpetr}} \leq P_{\mathrm{ESS}}^{\mathrm{dis,max}}\left(1-\partial_{\mathrm{ESS}, \text { cha }}\right),
\end{array}\right.
$$

where $Q_{\mathrm{ESS}, t}$ refers to the capacity of the energy storage system at time $t ; \lambda_{\text {ESS,cha }}$ and $\lambda_{\text {ESS,dis }}$ represent the energy storage and release efficiency of the energy storage system, respectively; $Q_{E S S}^{\max }$ denotes the maximum capacity of the energy storage system; and $\partial_{\mathrm{ESS}, \text { cha }}$ is the Boolean variable of the energy storage state of the energy storage system. When $\partial_{\text {ESS, cha }}=1$, the energy storage system stores energy; otherwise, it releases energy. $P_{\mathrm{ESS}}^{\text {chamax }}$ and $P_{\mathrm{ESS}}^{\mathrm{dis,max}}$ are the maximum value of energy storage and release of energy storage system, respectively. 
(5) Grid interaction constraints: the grid interaction constraint means that the VPP cannot exceed the maximum value when purchasing from and selling electricity to the grid:

$$
\left\{\begin{array}{l}
0 \leq P_{\text {grid }, b, t} \leq P_{\text {grid }}^{\max } \\
0 \leq P_{\text {grid }, s, t} \leq P_{\text {grid }}^{\max }
\end{array}\right.
$$

where $P_{\text {grid }}^{\max }$ refers to the maximum power that the VPP exchanges with the grid.

(6) Power balance constraint: power balance constraint refers to the balance between supply and demand in each period:

$$
\sum_{j=1}^{N_{w}^{\mathrm{wpetr}}} P_{w p p, t}^{j}+\sum_{j=1}^{N_{p v}^{\mathrm{wpetr}}} P_{p v, t}^{j}+\sum_{j=1}^{N_{D G}^{\mathrm{wp} p e t r}} P_{D G, t}^{j}+P_{r l, t}^{\mathrm{wpetr}}+P_{T l, t}^{\mathrm{wpetr}}+P_{\mathrm{ESS}, t}^{\mathrm{dis}, \mathrm{wpetr}}+P_{\mathrm{grid}, b, t}^{\mathrm{wpetr}}=P_{\text {load }, t}^{\mathrm{wpetr}}+P_{\mathrm{ESS}, t}^{\mathrm{cha}}+P_{\text {grid }, s, t}^{\mathrm{wpetr}}+P_{E V, t}^{\mathrm{wpetr}} .
$$

(7) Scene probability constraints: the scene probability constraint means that the sum of the probabilities of each scene is 1 , as shown in

$$
\left\{\begin{array}{l}
\sum_{i=1}^{n_{w}} \theta\left(w_{i}\right)=1, \\
\sum_{i=1}^{n_{p v}} \theta\left(P_{j}\right)=1, \\
\sum_{i=1}^{n_{E V}} \theta\left(e_{k}\right)=1, \\
\sum_{i=1}^{n_{T l}} \theta\left(t_{m}\right)=1, \\
\sum_{i=1}^{n_{r l}} \theta\left(r_{s}\right)=1 .
\end{array}\right.
$$

\section{Model Calculation and Solution}

To coordinate the multiobjective strategy for maximizing the net income of VPP and the clean energy consumption, the specific solution is as follows:

(1) Step 1: transform the maximization of net income and clean energy consumption into that of objective functions. Let $h_{1}=-f_{1}$ and $h_{2}=-f_{2}$, and the transformation result is shown in the following equations:

$$
\begin{aligned}
& \min h_{1}=\min \left(r_{\text {risk }}-R_{\text {net }}\right), \\
& \min h_{2}=\min -\left(\frac{\sum_{j=1}^{N_{w}^{w p e t r}} P_{w p p, t}^{j}+\sum_{j=1}^{N_{p v}^{w p e t r}} P_{p v, t}^{j}}{\sum_{j=1}^{N_{w}^{w p e t r}} P_{w p p, t}^{j}+\sum_{j=1}^{N_{p p e t r}^{w p}} P_{p v, t}^{j}+\sum_{j=1}^{N_{G D}^{w p e t r}} P_{D G, t}^{j}}\right) .
\end{aligned}
$$

(2) Step 2: use CPLEX to solve the optimal solutions under different objective functions, and count them as $h_{1}^{\min }$ and $h_{2}^{\min }$.

(3) Step 3: the fuzzy membership method is used to scalar the two objective functions. Among them, the optimal solution obtained by the solution is taken as the lower limit, and the maximum values of $h_{1}^{\max }$ and $h_{2}^{\max }$ in the single-objective optimization result are taken as the upper limit. The membership functions of the objective functions of $h_{1}$ and $h_{2}$ can be obtained based on the following equations:

$$
\begin{aligned}
& H_{1}= \begin{cases}0, & h_{1} \leq h_{1}^{\min }, \\
\frac{h_{1}-h_{1}^{\min }}{h_{1}^{\max }-h_{1}^{\min },} & h_{1}^{\min } \leq h_{1} \leq h_{1}^{\max }, \\
1, & h \geq h_{1}^{\max },\end{cases} \\
& H_{2}= \begin{cases}0, & h_{2} \leq h_{2}^{\min }, \\
\frac{h_{2}-h_{2}^{\min }}{h_{2}^{\max }-h_{2}^{\min },} & h_{2}^{\min } \leq h_{2} \leq h_{2}^{\max }, \\
1, & h \geq h_{2}^{\max } .\end{cases}
\end{aligned}
$$


(4) Step 4: use the weighted comprehensive index method to convert the multiple targets into the single target. The conversion result is shown in the following equation:

$$
\begin{aligned}
& \min H=\min \left(\varpi_{1} H_{1}+\varpi_{2} H_{2}\right) . \\
& \varpi_{1}+\varpi_{2}=1 .
\end{aligned}
$$

\section{Example Analysis}

5.1. Basic Data. Because of the rapid development of EVs and renewable energy in Shanxi Province, a certain area in Shanxi Province is taken as the example for empirical analysis. Specifically, select the wind speed, light intensity, EV charging load, interruptible load, and reduced load in the past three years from 2017-2019 to prepare 3 typical scene sets $n_{w}=n_{p v}=n_{E V}=n_{T l}=n_{r l}=3$, and all the scene probabilities are set at 0.33 . The specific situation is shown from Figures 2-6 [39, 40].

Figures 3 and 4 show the historical wind speed and light intensity from 2017 to 2019 , respectively. The horizontal axis represents the number of hours in a year, with a total time of 8760 hours. The ordinate corresponds to the wind speed and light intensity at different times. The data of 2017 are in black, the data of 2018 are in blue, and those of 2019 are in yellow.

Figures 5 and 6 show the historical interruptible load and transferable load from 2017 to 2019, respectively. The horizontal axis refers to the number of hours in a year, with a total time of 8760 hours. The ordinate corresponds to the interruptible load and transferable load at different times. The data of 2017 are in black, the data of 2018 are in red, and those of 2019 are in blue.

Figure 7 shows the average load from 2017 to 2019. The axis represents the number of hours in a year, with a total time of 8760 hours. The ordinate corresponds to the load at different times.

The prices for EV charging and user energy are based on time-of-use electricity prices, as shown in Table 3 [41].

The fine quantity set and environmental value of each pollutant are shown in Table 4 [42].

The specific parameters of wind turbines, photovoltaic panels, thermal generators, energy storage systems, and various types of EVs are shown in Table 5 [43].

Set the compensation cost of the transferable load at $0.0122 \$ / \mathrm{kW} \cdot \mathrm{h}$, and the compensation cost for interruptible load at $0.0183 \$ / \mathrm{kW} \cdot \mathrm{h}$. The VPP purchases electricity from the grid at the price of $10.1986 \$ / \mathrm{kW} \cdot \mathrm{h}$ and sells it to the grid at the price of $0.1604 \$ / \mathrm{kW} \cdot \mathrm{h}$. The coal price is $71.8160 \$ /$ ton, the discount rate is $8 \%$, and the degree of risk appetite is 1 . The weight coefficients for the maximization of net income and that of clean energy consumption are $50 \%$ and $50 \%$, respectively. There are a total of 8,000 EVs for which electric taxis, electric buses, and electric private cars account $40 \%, 20 \%$, and $40 \%$, respectively.

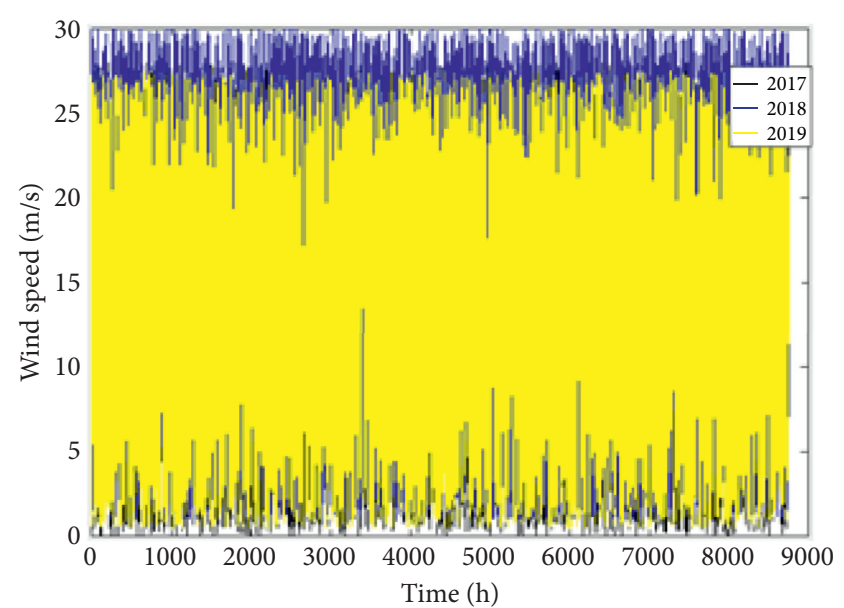

Figure 3: Historical data of wind speed in 2017-2019.

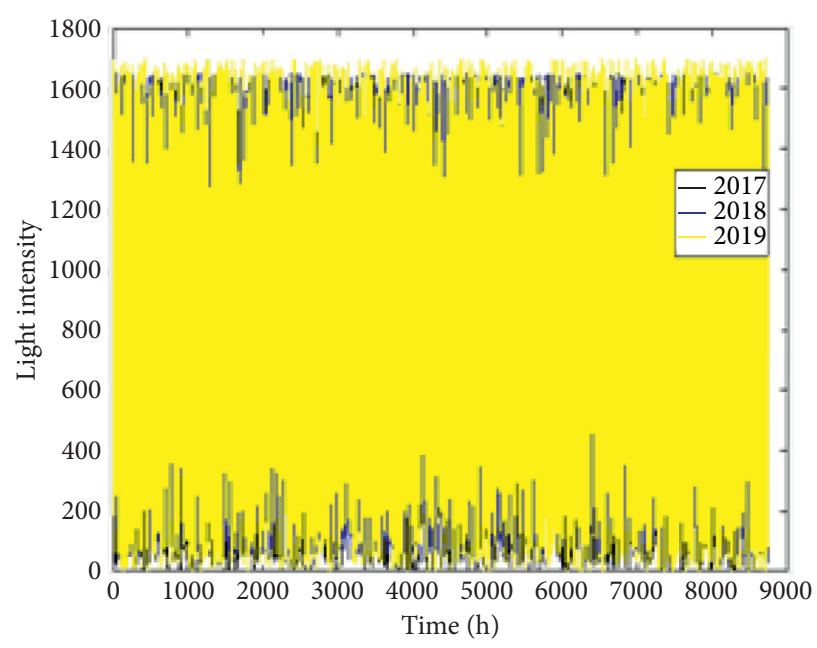

FIgURE 4: Historical data of light intensity in 2017-2019.

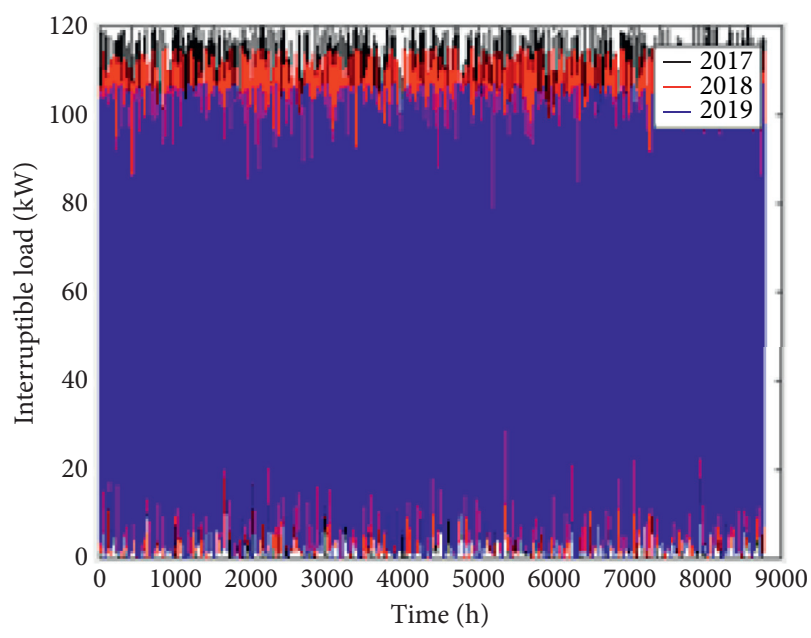

Figure 5: Historical data of interruptible load in 2017-2019. 


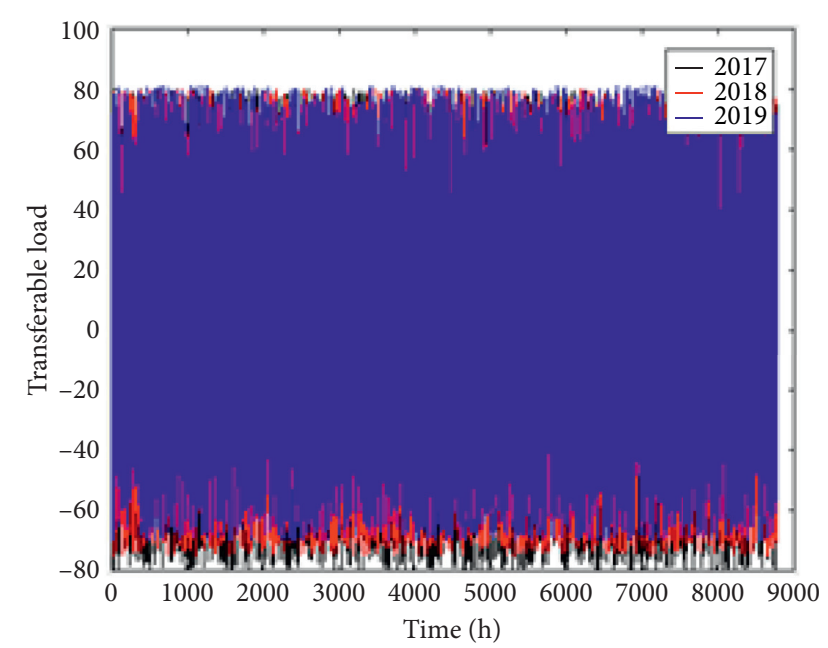

Figure 6: Historical data of transferable load in 2017-2019.

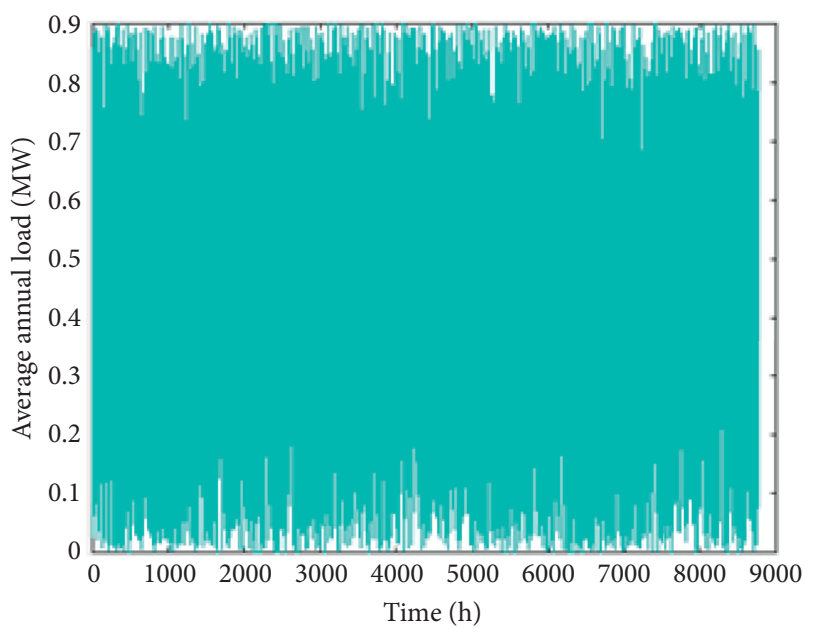

Figure 7: Average annual load data for 2017-2019.

\subsection{Example Results}

5.2.1. Analysis of the Impact of EV Access on Capacity Allocation Results. To study the impact of EVs on the VPP's optimal configuration, the impact of different EV access scales on VPP capacity configuration is first analyzed, which is followed by the analysis of each unit.

(1) Analysis of the impact of different EV access scales on capacity allocation results: when $100 \%$ of EVs are connected to the VPP, a total of 8,000 vehicles will be set, and the connection ratio varies between $50 \%$ and $120 \%$. And through CPLEX to optimize the solution, with 1 hour as the step size for simulation, the simulation results stabilized after 48 iterations, and the optimized calculation time was 10.4 seconds. The capacity configuration optimization results are shown in Table 6.

As shown in Table 6, with the continuous increase of the scale of EV access, the net income, clean energy consumption value, and comprehensive objective function value of VPP all increase first and then decrease. This is due to the fact that the increase in the scale of EV access has led to an increase in the charging load demand of EVs. To maintain the balance between supply and demand, the VPP has to increase its output and the number of units configured. When the scale of EV access is [50\%, 80\%], the wind turbines and photovoltaic panels are increased to meet the requirements of the increased charging load, and the clean energy consumption rate will increase at this time. At the same time, because the increase in charging load is greater than the increased cost of the VPP, the net income of the VPP increases.

In the case that the scale of EV access is [80\%, 100\%], the increase in wind turbines and photovoltaic panels is less, and that in thermal power generation and energy storage systems is greater. The increased charging load is mainly met by thermal power generating sets and energy storage systems. This is because that the greatly increased demand for EV charging has greatly increased the risk of disorderly charging. To ensure the safety and reliability of power supply, the selected output is more reliable for the thermal power generating units and energy storage systems to meet. Therefore, on the one hand, this reduces the consumption rate of clean energy. On the other hand, due to the high investment and construction cost of the energy storage system, the net income of the VPP is reduced.

It can also be seen from Table 4 that the number of fastcharging piles is higher than that of slow-charging piles. The reason is that electric buses and taxis usually use fastcharging methods due to the operating hours, while private cars usually use slow-charging methods. The proportions of various types of EVs are $40 \%, 20 \%$, and $40 \%$, respectively, which means that the scale of electric buses and electric taxis is larger than that of private cars. Therefore, in the VPP capacity configuration results, the number of fast-charging piles is greater than that of slow-charging piles.

From Table 6 and related analysis, it can be seen that when the scale of electric vehicles is $80 \%$, the net income and clean energy consumption rate of the virtual power plant are the highest, and the maximum comprehensive objective function value is 0.4988 . Therefore, under the current conditions, the optimal ratio of electric vehicles connected to the virtual power plant is $80 \%$.

When the access scale of electric vehicles exceeds $100 \%$, the net income and clean energy consumption rate of the virtual power plant will decrease compared with the scale not exceeding $100 \%$. This is because the scale of more than $100 \%$ will lead to an increase in charging and discharging power, and more standby units need to be configured in the virtual power plant to ensure the safe and stable operation of the virtual power plant. However, if these electric vehicles can be guided in an orderly way, the net income and clean energy consumption rate may exceed the scenario that the scale of access is less than $100 \%$.

(2) Result analysis of VPP output: when selecting a typical day of $2592-2615 \mathrm{~h}$ and analyzing the EV access ratio of $80 \%$, the output of each unit of the VPP is shown in Figure 8.

According to Figure 8, the time frames from $1-5 \mathrm{~h}$ to 13 $14 \mathrm{~h}$ refer to the low electricity consumption period, the 
TABLE 3: EV charging price and user energy price list.

\begin{tabular}{lccc}
\hline & Time division & EV charging price $(\$ / \mathrm{kW} \cdot \mathrm{h})$ & User energy price $(\$ / \mathrm{kW} \cdot \mathrm{h})$ \\
\hline Peak period & $9: 00-14: 00,18: 00-21: 00$ & 0.17 & 0.16 \\
Flat period & $6: 00-9: 00,14: 00-18: 00$ & 0.14 & 0.13 \\
Valley period & $21: 00-6: 00$ & 0.11 & 0.10 \\
\hline
\end{tabular}

TABLe 4: The set of fines for each pollutant and its environmental value.

\begin{tabular}{lccc}
\hline- & Pollutant discharge $(\mathrm{g} / \mathrm{kW} \cdot \mathrm{h})$ & Fine quantity $(\$ / \mathrm{kg})$ & Environmental value $(\$ / \mathrm{kg})$ \\
\hline $\mathrm{NO}_{x}$ & 4.55 & 0.1247 & 0.7484 \\
$\mathrm{CO}_{2}$ & 234.08 & 0.2494 & 0.9978 \\
$\mathrm{CO}$ & 2.36 & 0.0012 & 0.0028 \\
$\mathrm{SO}_{2}$ & 0.48 & 0.0200 & 0.1247 \\
\hline
\end{tabular}

TABLE 5: Specific parameters of each unit.

\begin{tabular}{|c|c|c|c|}
\hline \multicolumn{2}{|l|}{ Wind turbine } & \multicolumn{2}{|l|}{$\mathrm{EV}$} \\
\hline Cut-in wind speed & $3 \mathrm{~m} / \mathrm{s}$ & Taxi mean & 6.00 \\
\hline Cut-out wind speed & $21 \mathrm{~m} / \mathrm{s}$ & Taxi standard deviation & 0.83 \\
\hline Rated wind speed & $11 \mathrm{~m} / \mathrm{s}$ & Bus mean & 5.50 \\
\hline Maximum power & $300 \mathrm{~kW}$ & Bus standard deviation & 0.27 \\
\hline Minimum climbing rate & 0.2 & Private car mean & 7.51 \\
\hline Maximum climbing rate & 0.8 & Private car standard deviation & 0.37 \\
\hline Cost of investment construction & $1222.40 \$ / \mathrm{kW}$ & Cost of investment construction cost & $1528.00 \$$ \\
\hline Operation and maintenance factor & 0.03 & Operation and maintenance factor & $\begin{array}{l}0.05 \text { (fast); } 0.03 \\
\quad \text { (slow) }\end{array}$ \\
\hline Operating life & 20 years & Operating life & 20 \\
\hline \multicolumn{2}{|l|}{ Photovoltaic panels } & \multicolumn{2}{|c|}{ Energy storage system } \\
\hline Maximum power & $200 \mathrm{~W}$ & Rated capacity & $1000 \mathrm{Ah}$ \\
\hline Photoelectric conversion efficiency & $14.28 \%$ & Maximum power of energy storage & $100 \mathrm{~kW}$ \\
\hline Photovoltaic panel area & $0.25 \mathrm{~m}^{2}$ & Maximum power of energy discharge & $100 \mathrm{~kW}$ \\
\hline Investment construction cost & $1833.60 \$ / \mathrm{kW}$ & Energy storage efficiency & $85 \%$ \\
\hline Operation and maintenance factor & 0.04 & Cost of investment construction & $305.60 \$ / \mathrm{kW}$ \\
\hline Operating life & 20 years & Operating life & 18 years \\
\hline \multicolumn{4}{|c|}{ Thermal power generating set } \\
\hline Minimum climbing rate & 0.2 & $a$ & 0.01 \\
\hline Maximum climbing rate & 0.8 & $b$ & 0.02 \\
\hline Cost of investment construction cost & $764.00 \$ / \mathrm{kW}$ & c & 0.005 \\
\hline Operation and maintenance factor & 0.01 & Operating life & 20 years \\
\hline Operating life & 20 & & \\
\hline
\end{tabular}

TABLe 6: Different EV access to capacity allocation results.

\begin{tabular}{|c|c|c|c|c|c|c|c|c|}
\hline & $50 \%$ & $60 \%$ & $70 \%$ & $80 \%$ & $90 \%$ & $100 \%$ & $110 \%$ & $120 \%$ \\
\hline$N_{w}^{\text {wpetr }}$ & 8 & 10 & 12 & 14 & 15 & 15 & 16 & 16 \\
\hline$N_{p v}^{\text {wpetr }}$ & 4 & 5 & 6 & 7 & 7 & 8 & 8 & 9 \\
\hline$N_{D G}^{\text {wpetr }}$ & 3 & 4 & 6 & 8 & 11 & 15 & 16 & 16 \\
\hline$N_{\text {ESS }}^{\text {wpetr }}$ & 2 & 2 & 3 & 4 & 6 & 9 & 9 & 10 \\
\hline$N_{q E V}^{\text {wpetr }}$ & 30 & 38 & 45 & 52 & 60 & 70 & 78 & - \\
\hline$N_{s E V}^{\text {wpetr }}$ & 22 & 24 & 27 & 38 & 42 & 53 & 59 & 67 \\
\hline$f_{1}^{S L V}$ & 3.76 & 4.89 & 5.92 & 6.69 & 6.01 & 5.47 & 5.32 & 5.08 \\
\hline$f_{2}$ & $71 \%$ & $75 \%$ & $77 \%$ & $78 \%$ & $70 \%$ & $61 \%$ & $58 \%$ & $56 \%$ \\
\hline$H$ & 0.3941 & 0.4428 & 0.4726 & 0.4988 & 0.4813 & 0.4592 & 0.4439 & 0.4397 \\
\hline
\end{tabular}

output is greater than the energy consumption, and the interruptible load is 0 . The energy storage system is called first to store energy; however, the thermal power generation unit shows less output which maintains at around $400 \mathrm{~kW}$.
The remaining power is sold to the grid. The time frames from $9-14$ h to $18-22$ h represent the peak electricity consumption period when the output is less than the energy consumption, and the energy storage system is given the 


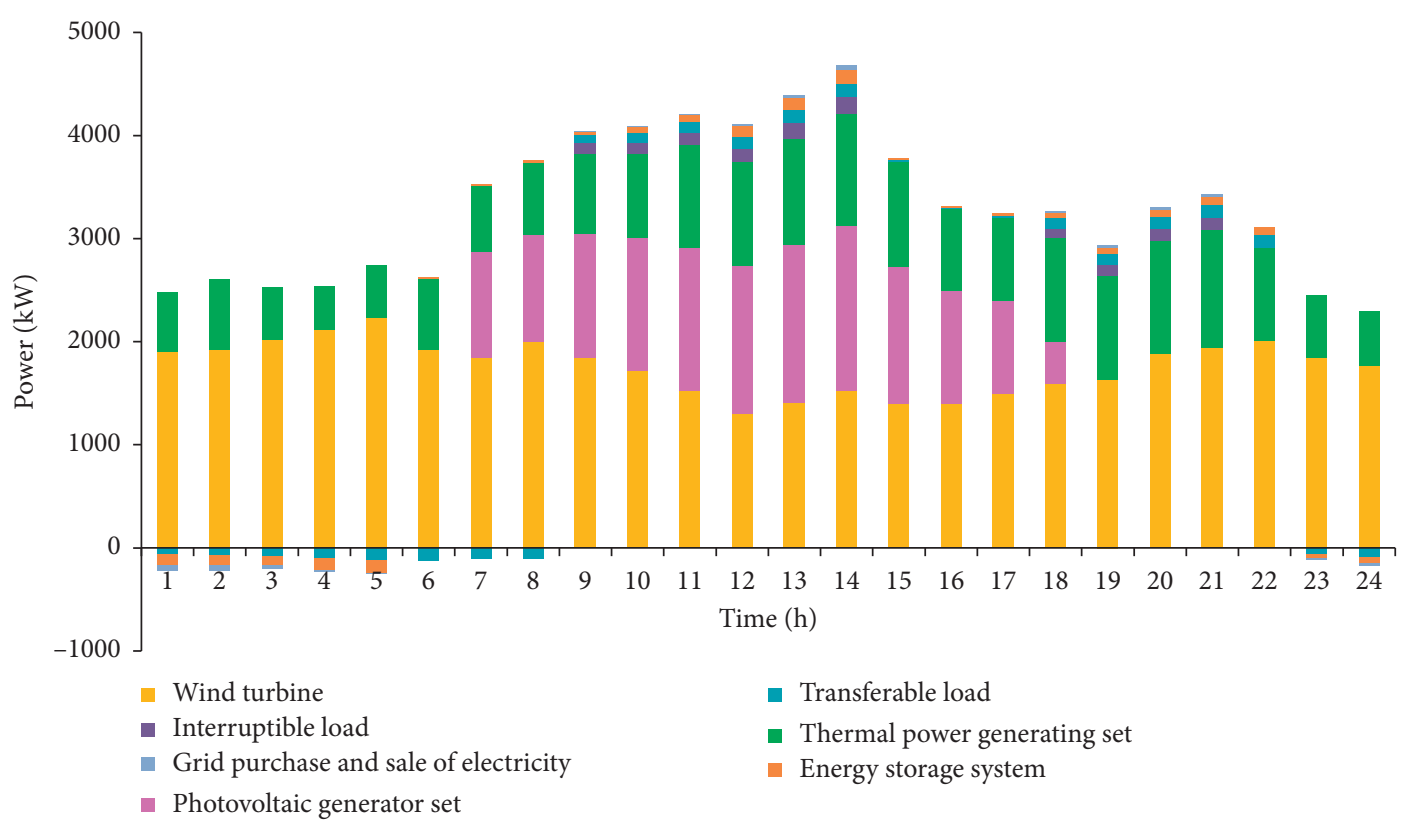

FIgURE 8: VPP output results on a typical day.

priority to discharge, thereby satisfying the load demand. On the one hand, part of the load is interrupted and transferred to the valley period; besides, the interrupted load is maintained at about $134 \mathrm{~kW}$. In the meantime, the output of thermal power generator sets is increased from $400 \mathrm{~kW}$ in the valley period to about $1000 \mathrm{~kW}$. And the shortfall is purchased from the grid.

\subsubsection{Analysis of Capacity Allocation Results under Different} Risk Preferences. The EV access ratio is set at $80 \%$, and the risk preference coefficient varies between $[0.25,1.50]$. The result of capacity optimization configuration is shown in Figure 9.

As shown in Figure 9, as the risk preference coefficient increases from 0.25 to 1.50 , the CVaR value gradually decreases, reflecting the increase in investors' aversion to risk. In another word, when the risk preference coefficient is relatively small, while the number of wind turbines and photovoltaic panels is large, thermal power generation sets are mainly used to reduce the uncertainty of renewable energy output. Since the cost of energy storage technology is relatively high and the cost of VPP can be reduced through thermal power generation units, the configuration optimization results include more thermal power generation units and less energy storage systems. However, when the degree of risk preference is large, to reduce the uncertainty of the system, the number of wind turbines and photovoltaic panels is reduced. On the other hand, to meet the load demand, the energy storage system and thermal power generator set are required to meet the demand of the shortfall load. At this time, the number of energy storage systems and thermal power generator sets is large.

\subsubsection{Considering the Influence of Multiobjective and Electric} Vehicle Access on VPP. In order to further analyze and consider the impact of multiobjective and electric vehicle access on the VPP, this paper sets four scenarios as shown in Table 7 for example analysis.

It can be seen from Table 6 that scenario 2 and scenario 3 configure the capacity of the virtual power plant with a single objective; scenario 1 and scenario 4 configure the capacity of the virtual power plant with multiple objectives. The objective function values of virtual power plants under different scenarios are shown in Table 8 .

According to Table 7, compared with the single objective, the optimal solution can be obtained by considering the optimal configuration of multiobjective virtual power plant compared with the single objective. The comprehensive effect is 0.4988 . However, scenario 3 with the highest clean energy consumption rate has the lowest comprehensive target value of 0.4702 .

The equivalent load curve and output of each unit under different scenarios are further analyzed, as shown in Figures 10-13. The equivalent load curve of virtual power plant is the superposition of total output and total load of virtual power plant.

As can be seen from Figures 10-13, scenario 2 only considers the maximization of net income. At this time, because the output of conventional thermal power units is stable, it will increase the output of conventional thermal power units and reduce the consumption of clean energy. For scenario 3, which only considers the maximum clean energy consumption, in order to maximize the clean energy consumption, the output of thermal power generation units will be reduced. However, in order to ensure the security and stability of the system, more reserve capacity needs to be configured, which reduces the economy of the system. Compared with scenario 4 , the equivalent load of virtual power plant in scenario 1 is steeper. The peak-valley difference of scenario 1 is $175.5 \mathrm{kw}$, which is much larger than that of scenario 4. The increase of peak-valley difference leads to the increase of operation and maintenance cost of 


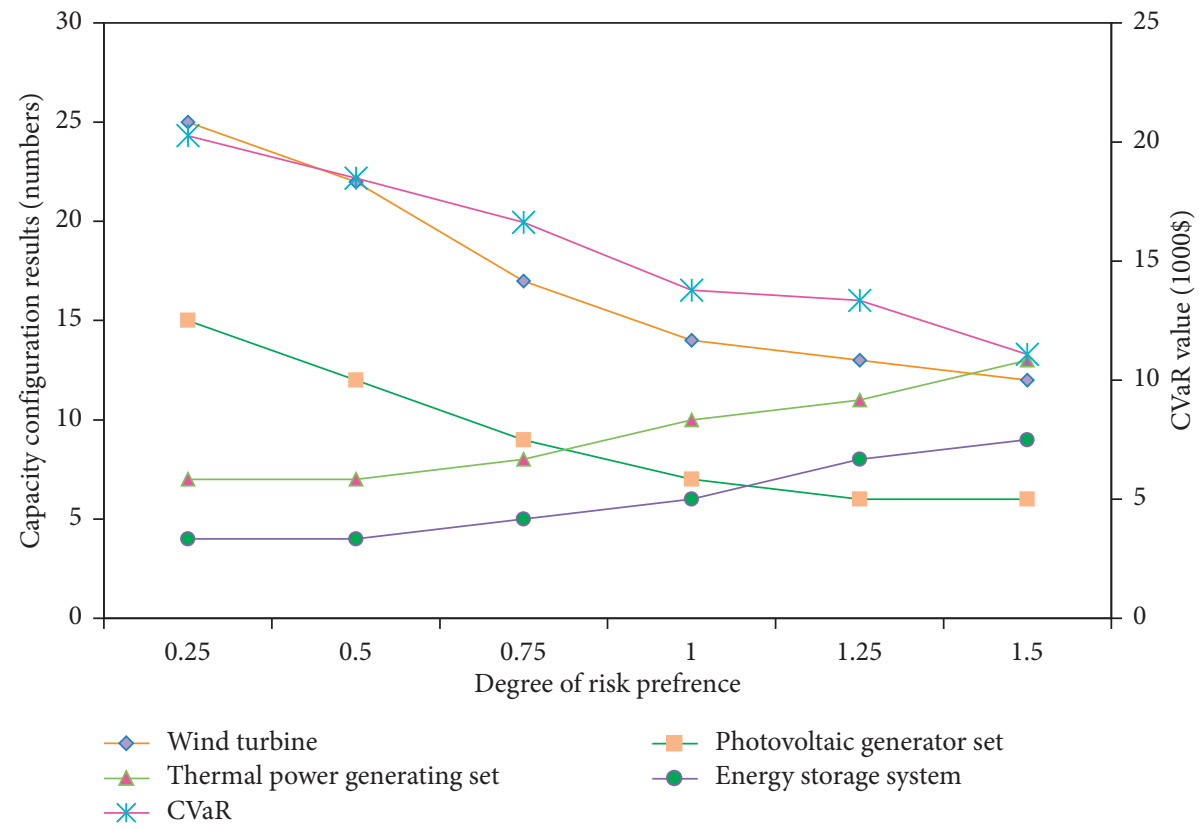

FIgURE 9: Capacity allocation results under different risk appetite levels.

TABle 7: Scenario setting.

\begin{tabular}{lccc}
\hline Scenario & Access to electric vehicles & Maximize net income & Maximize clean energy consumption \\
\hline Scenario 1 & $\times$ & $\sqrt{ }$ & $\sqrt{ }$ \\
Scenario 2 & $\sqrt{ }$ & $\sqrt{ }$ & $\times$ \\
Scenario 3 & $\sqrt{ }$ & $\times$ & $\sqrt{ }$ \\
Scenario 4 & $\sqrt{ }$ & $\sqrt{ }$ & $\sqrt{ }$ \\
\hline
\end{tabular}

TABLE 8: Objective function values in different scenarios.

\begin{tabular}{lccc}
\hline Scenario & Access to electric vehicles & Maximize net income (\%) & Maximize clean energy consumption \\
\hline Scenario 1 & 6.01 & 62 & 0.4721 \\
Scenario 2 & 6.84 & 66 & 0.4719 \\
Scenario 3 & 5.72 & 85 & 0.4702 \\
Scenario 4 & 6.69 & 78 & 0.4988 \\
\hline
\end{tabular}
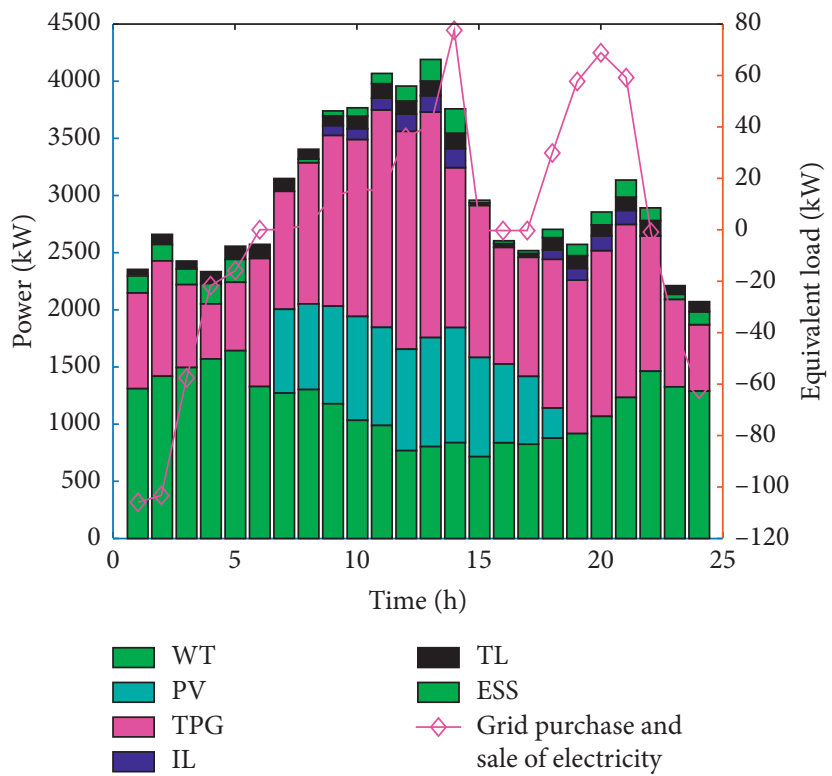

Figure 10: Equivalent load and output curve under scenario 1. 


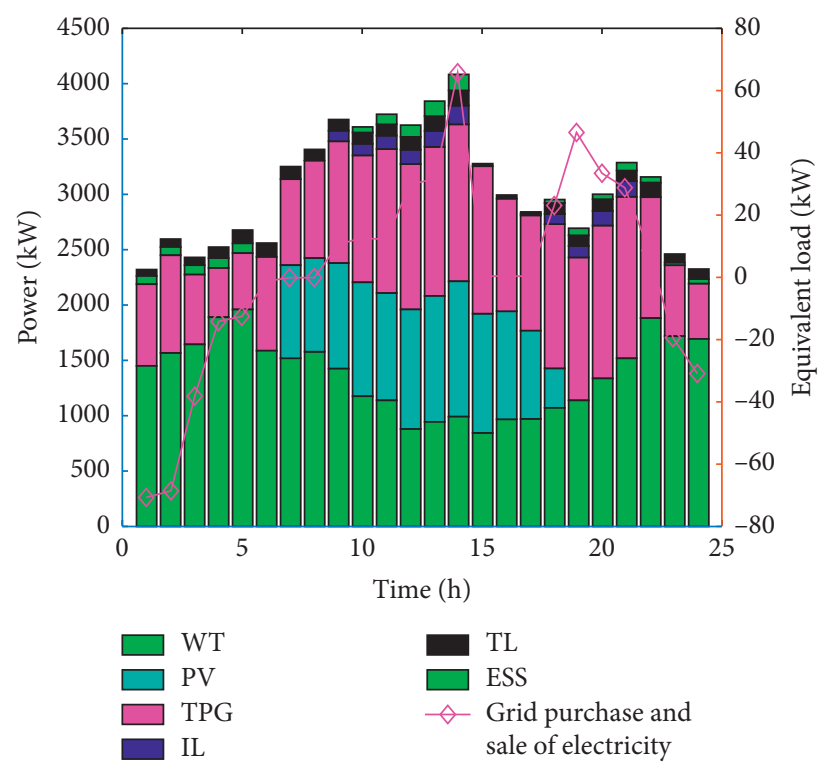

Figure 11: Equivalent load and output curve under scenario 2.

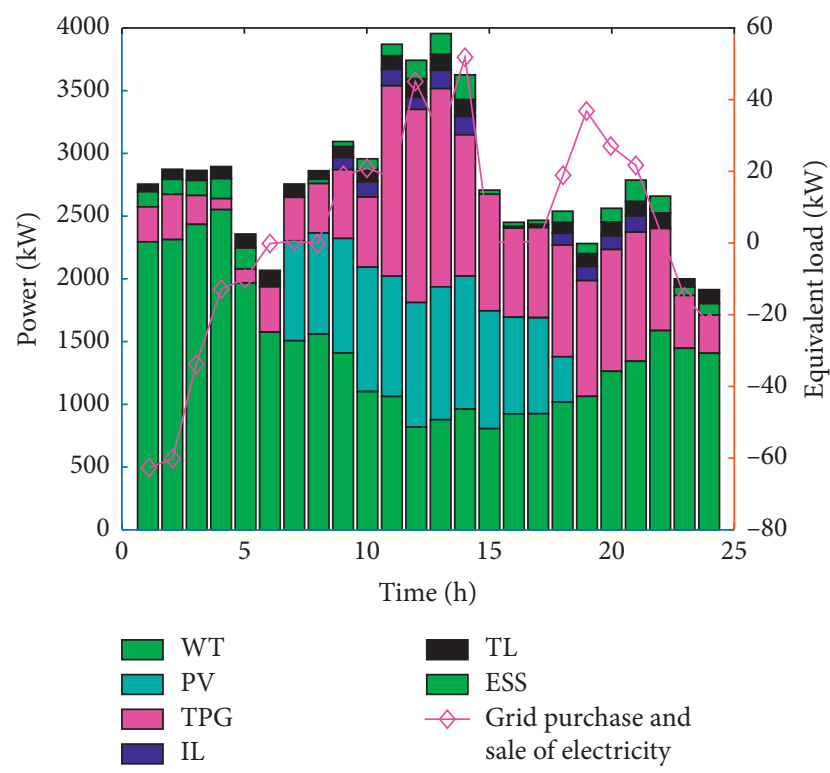

FIgURE 12: Equivalent load and output curve under scenario 3.

virtual power plant, which reduces the net income of virtual power plant. It shows that the peak-valley difference can be effectively reduced when the electric vehicle is connected to the virtual power plant and guided orderly.

\subsubsection{Sensitivity Analysis of the Influence of Different Target} Weight Coefficients on the Capacity Allocation Results. The weight coefficient for maximizing net income and clean energy consumption is changed for sensitivity analysis. When the weight coefficients reach $50 \%$, it means that the ratio of the importance for maximizing net income and clean energy consumption is 1 . Allowing the importance of the

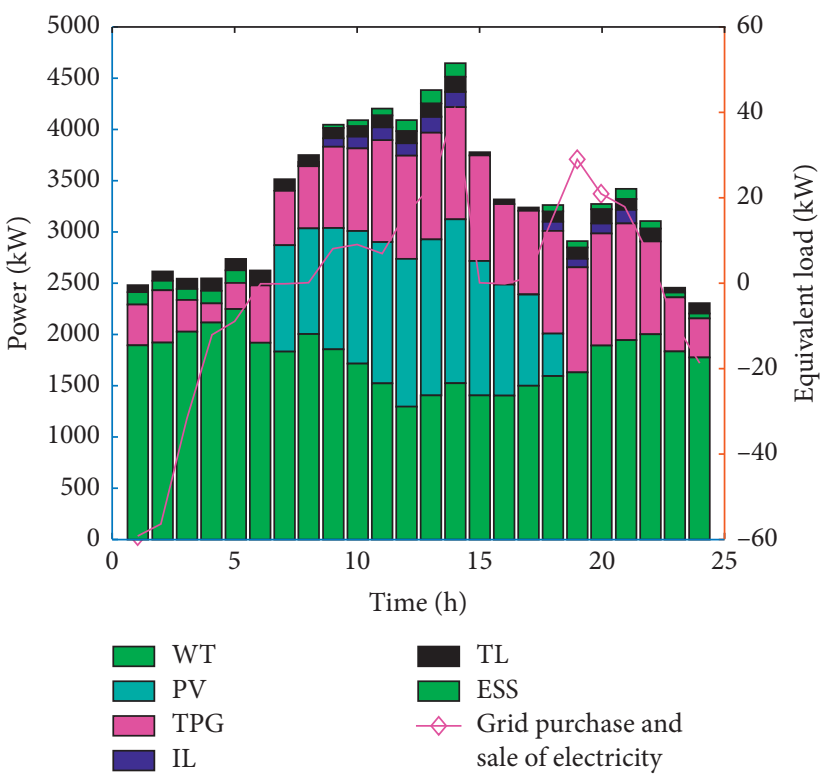

Figure 13: Equivalent load and output curve under scenario 4.

two to change between $[0.5,5]$, the sensitivity analysis results are shown in Figure 14.

As shown in Figure 14, as the ratio of the importance of maximizing net income to maximizing clean energy consumption increases, the value of net income first increases and then decreases, while the proportion of clean energy consumption continues to decline. This is because that as the importance ratio increases, the VPP based on the economic net income value will increase the proportion of thermal power generation output and reduce the uncertainty of clean energy output. At this time, the proportion of clean energy consumption will decrease. However, when the importance ratio increases to 3 , the output of thermal power generating 


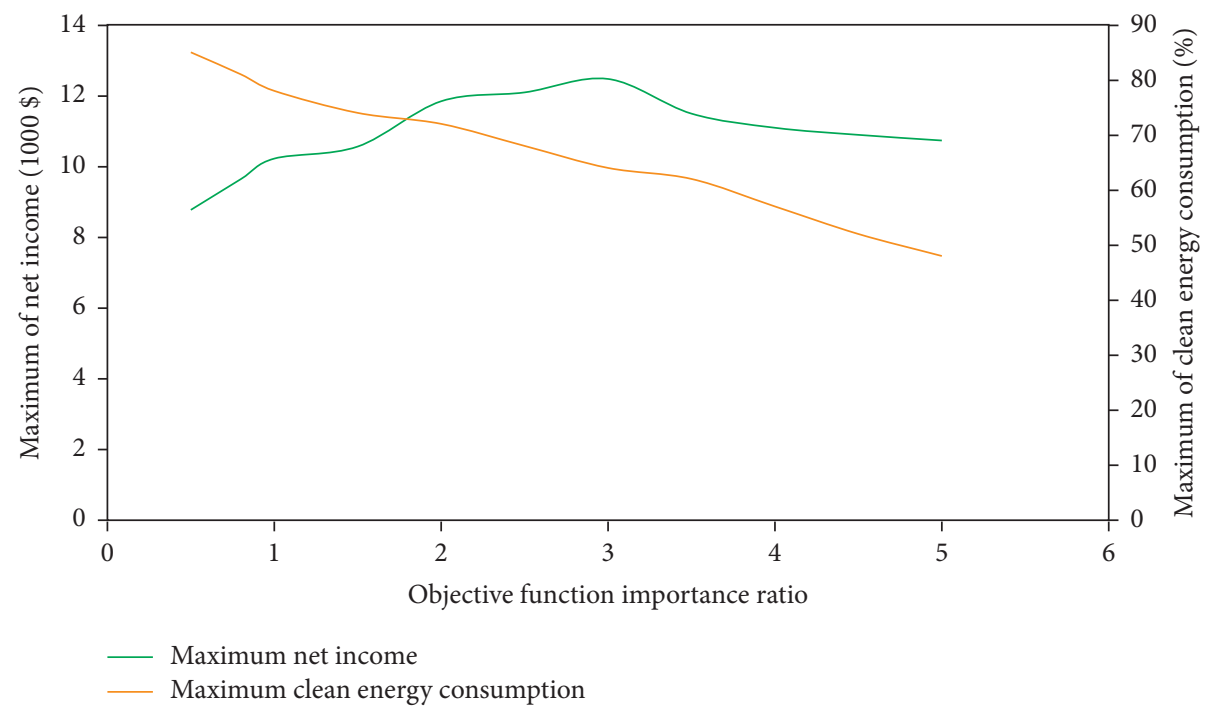

FIGURE 14: Sensitivity analysis chart.

units will account for a relatively high proportion, leading to a faster increase in environmental costs, and exceeding the benefits it brings in. In the meantime, the net income begins to decline at this time. The results of this optimized configuration show that the requirements of economy and environmental protection should be coordinated according to the requirements of the country's external policy environment, thus maximizing the comprehensive income value of the VPP.

\section{Results and Conclusions}

To enrich the research results of capacity configuration, this paper first takes the VPP capacity configuration as the research object, including EVs, which is followed by the modeling of each part of the VPP. Aiming at the reduction of the uncertainty of wind power generation, photovoltaic power generation, EV charging, and load, the problem of uncertainty is transformed into that of certainty with the scene generation method. To take into account the economics and environmental protection of VPP, and the uncertainty of investors' income, conditional value-at-risk was introduced, thereby constructing a multiobjective capacity optimization model with net income and clean energy consumption maximization. Meanwhile, Shanxi Province is taken as an example for the analysis of the calculation example, and the results are as follows:

(1) For VPP that includes EVs, the optimal scale of EV access should be selected reasonably to achieve the highest comprehensive income of VPP. As the scale of EV access increases, on the one hand, the demand for EV charging increases, leading to the increase of the revenue of VPP. On the other hand, the security of VPP and the cost of capacity allocation are reduced. Therefore, it is necessary to select the scale of access reasonably to achieve a balance between benefits and costs.

(2) The risk aversion of decision-makers increases with the increase of the risk preference coefficient.
Therefore, when the risk preference coefficient is relatively small, the number of wind turbines and photovoltaic panels becomes relatively large. In contrast, when the risk preference is relatively large, the number of energy storage systems and thermal power generating sets becomes relatively large.

(3) As the importance ratio of maximizing net income to maximizing clean energy consumption increases, the value of net income first increases and then decreases, while the proportion of clean energy consumption continues to decline. Therefore, decisionmakers should fully consider the country's external environmental requirements and coordinate the balance between the economy and environmental protection of VPP.

\section{Data Availability}

The basic data used to support the findings of this study are included in the paper.

\section{Conflicts of Interest}

The authors declare that they have no conflicts of interest.

\section{References}

[1] Y. Mu, J. Wu, N. Jenkins, H. Jia, and C. Wang, "A spatialtemporal model for grid impact analysis of plug-in electric vehicles," Applied Energy, vol. 114, pp. 456-465, 2014.

[2] Z. L. Wei, S. Yu, G. Q. Sun et al., "Concept and development of VPP," Automation of Electric Power Systems, vol. 37, no. 13, pp. 1-9, 2013.

[3] X. Y. Kong, J. Xiao, and D. H. Liu, "Robust stochastic optimal dispatching method of multi-energy VPP considering multiple uncertainties," Applied Energy, vol. 279, Article ID 115707, 2020.

[4] J. Chen, Y. T. Liu, and W. Zhang, "Optimal sizing analysis of multilevel microgrids in distribution network based on game 
theory," Automation of Electric Power Systems, vol. 40, no. 1, pp. $45-52,2016$.

[5] N. T. Huang, J. R. Q. Bao, and G. W. Cai, "Multi-agent joint investment microgrid source-storage multi-strategy bounded rational decision evolution game capacity planning," Proceedings of the CSEE, vol. 40, no. 4, pp. 1212-1225, 2020.

[6] K. P. Li, Z. Y. Zhang, and F. Wang, "Stochastic optimization model of capacity configuration for stand-alone microgrid based on scenario simulation using GAN and conditional value at risk," Power System Technology, vol. 43, no. 5, pp. 1717-1725, 2019.

[7] M. D. Xue, B. Zhao, and X. S. Zhang, "Integrated plan and evaluation of grid connected microgrid," Automation of Electric Power Systems, vol. 39, no. 3, pp. 6-13, 2015.

[8] X. Zhang, M. Shahidehpour, A. S. Alabdulwahab, and A. Abusorrah, "Security-constrained co-optimization planning of electricity and natural gas transportation infrastructures," IEEE Transactions on Power Systems, vol. 30, no. 6, pp. 2984-2993, 2015.

[9] D. Maraver, A. Sin, F. Sebastián, and J. Royo, "Environmental assessment of CCHP (combined cooling heating and power) systems based on biomass combustion in comparison to conventional generation," Energy, vol. 57, pp. 17-23, 2013.

[10] S. F. Lin, C. T. Liu, and D. D. Li, "Dual-layer and multiscenario collaborative optimization configuration for multimicrogrid systems in cooling, heating and power areas considering electric energy interaction," Proceedings of the CSEE, vol. 40, no. 5, pp. 1409-1421, 2020.

[11] X. Y. Ma, X. B. Guo, and J. Y. Lei, "Distributed photovoltaic and gas-electric hybrid capacity planning method for multienergy complementary," Automation of Electric Power Systems, vol. 42, no. 4, pp. 55-63, 2018.

[12] Z. L. Yao and Z. X. Wang, "Two-level collaborative optimization configuration method of integrated energy system taking into account wind and wind uncertainty," Power System Technology, vol. 14, no. 5, pp. 1-13, 2020.

[13] W. Huang, N. Zhang, and J. W. Yang, "Optimal configuration planning of multi-energy systems considering distributed renewable energy," IEEE Transactions on Smart Grid, vol. 10, no. 2, pp. 1452-1464, 2019.

[14] H. Xiao, W. Pei, W. Pei, Z. Dong, and L. Kong, "Bi-level planning for integrated energy systems incorporating demand response and energy storage under uncertain environments using novel metamodel," CSEE Journal of Power and Energy Systems, vol. 4, no. 2, pp. 155-167, 2018.

[15] W. X. Liu, Z. Z. Li, and Y. Yang, "Collaborative optimization configuration of integrated energy system considering uncertainty of demand response," Automation of Electric Power Systems, vol. 44, no. 10, pp. 41-53, 2020.

[16] B. Zeng, X. Wei, D. Zhao, C. Singh, and J. Zhang, "Hybrid probabilistic-possibilistic approach for capacity credit evaluation of demand response considering both exogenous and endogenous uncertainties," Applied Energy, vol. 229, pp. 186-200, 2018.

[17] Z. X. Jing, R. X. Hu, and Z. X. Yuan, "Optimized configuration of island microgrid with wind/solar/pumped storage and load response," Automation of Electric Power Systems, vol. 41, no. 1, pp. 65-72+116, 2017.

[18] H. Fan, Q. Q. Yuan, and J. Deng, "Two-stage capacity optimization configuration method for multi-region integrated energy system," Modern Electric Power, vol. 37, no. 5, pp. 441-449, 2020.

[19] X. Y. Huang, J. Li, and L. Yang, "Multi-power capacity configuration of VPP based on investment portfolio,"
Automation of Electric Power Systems, vol. 39, no. 19, pp. 75-81, 2015.

[20] K. Elaine, M. Hart, and Z. Jacobson, "A Monte Carlo approach to generator portfolio planning and carbon emissions assessments of systems with large penetrations of variable renewable," Renewable Energy, vol. 36, no. 8, pp. 2278-2286, 2011.

[21] Z. D. Shi, W. S. Wang, and Y. H. Huang, "Stratified optimization planning method for power storage and heat storage capacity of multi-energy complementary power generation system," Power System Technology, vol. 44, no. 9, pp. 32633271, 2020.

[22] Y. Zheng, J. P. Zhu, and Y. Yuan, "Economic risk assessment of wind diesel storage island microgrid based on conditional value at risk," Electric Power Automation Equipment, vol. 39, no. 11, pp. 57-63, 2019.

[23] H. X. Guo, R. Gao, and P. Yang, "Two-stage dispatch of microgrid spot market based on conditional value-at-risk," Power System Technology, vol. 43, no. 8, pp. 2665-2674, 2019.

[24] P. Y. Gao, X. Y. Zhao, and F. Yao, "Modeling of charging load considering the temporal and spatial distribution of electric vehicles," Journal of Electric Power Science and Technology, vol. 34, no. 3, pp. 47-55, 2019.

[25] H. B. Wang, C. M. Wang, and G. W. Zhang, "Two-stage stochastic generation dispatching model and method considering conditional value-at-risk," Proceedings of the CSEE, vol. 36, no. 24, pp. 6838-6848, 2016, in Chinese.

[26] H. D. Liu, Z. Q. Feng, and J. Q. Wang, "Economic dispatch of integrated energy system considering conditional value- atrisk," Power System Technology, vol. 42, no. 5, pp. 1385-1392, 2018.

[27] W. Yang, S. Zhao, and Z. Zhi, "Risk adjustable day-ahead unit commitment with wind power based on chance constrained goal programming," IEEE Transactions on Sustainable Energy, vol. 8, no. 2, pp. 530-541, 2017.

[28] N. Zhang, C. Kang, Q. Xia et al., "A convex model of riskbased unit commitment for day-ahead market clearing considering wind power uncertainty," IEEE Transactions on Power Systems, vol. 30, no. 3, pp. 1582-1592, 2015.

[29] Z. N. Wei, Y. Chen, and W. J. Huang, "Optimal allocation model for multi-energy capacity of VPP considering conditional value-at-risk," Automation of Electric Power Systems, vol. 42, no. 4, pp. 39-46, 2018.

[30] H. B. Wang, J. Wang, and C. M. Wang, "Risk-constrained energy management modeling of VPP," Proceedings of the CSEE, vol. 37, no. 20, pp. 5942-5950, 2017.

[31] Y. Wang, Z. Shi, and Z. Wang, "Dynamic scheduling optimization model for VPP connecting with windphotovoltaicenergy storage system," in Proceedings of the 2017 IEEE Conferenceon Energy Internet and Energy System Integration, pp. 1-6, IEEE, Beijing, China, November 2017.

[32] L. Ju, H. Li, J. Zhao, K. Chen, Q. Tan, and Z. Tan, "Multiobjective stochastic scheduling optimization model for connecting a virtual power plant to wind-photovoltaic-electric vehicles considering uncertainties and demand response," Energy Conversion and Management, vol. 128, pp. 160-177, 2016.

[33] E. G. Kardakos, C. K. Simoglou, and A. G. Bakirtzis, "Optimal offering strategy of a VPP: a stochastic bi-level approach," IEEE Transactions on Smart Grid, vol. 7, no. 2, pp. 794-806, 2016.

[34] E. Nasrolahpour, J. Kazempour, H. Zareipour, and W. D. Rosehart, "Impacts of ramping inflexibility of conventional generators on strategic operation of energy storage 
facilities," IEEE Transactions on Smart Grid, vol. 9, no. 2, pp. 1334-1344, 2018.

[35] D. N. Liu, M. G. Liu, W. Wang et al., "Operation model and key technology of charging load aggregator participating in green certificate transaction," Automation of Electric Power Systems, vol. 44, no. 10, pp. 1-9, 2020.

[36] D. Lu, Y. Yuan, and S. Yang, "Operational risk assessment of independent wind solar diesel storage microgrid based on Markov chain Monte Carlo method," Power System Technology, vol. 41, no. 3, pp. 823-830, 2017.

[37] J. Y. Zhu, Y. Liu, and L. X. Xu, "Robust day-ahead economic dispatch of microgrid with combined heat and power system considering wind power accommodation," Automation of Electric Power Systems, vol. 43, no. 4, pp. 40-48, 2019.

[38] S. M. Nosratabadi, R.-A. Hooshmand, and E. Gholipour, "A comprehensive review on microgrid and virtual power plant concepts employed for distributed energy resources scheduling in power systems," Renewable and Sustainable Energy Reviews, vol. 67, pp. 341-363, 2017.

[39] S. P. Geng, D. X. Niu, and X. P. Guo, "Multi-objective evolutionary game of micro-energy grids considering multi-energy flexible load dispatch," Electric Power Construction, vol. 41, no. 11, pp. 101-115, 2020.

[40] Z. L. Wei, Y. Chen, and W. J. Huang, "Optimal configuration model of VPP's multi-power supply capacity considering conditional value-at-risk," Automation of Electric Power Systems, vol. 42, no. 4, pp. 39-46, 2018.

[41] G. L. Yuan and W. F. Su, "Research on virtual power plant participating in AGC frequency modulation service considering the uncertainty of electric vehicles," Power System Technology, vol. 44, no. 7, pp. 2538-2548, 2020.

[42] Y. F. Wang, W. J. Gao, F. Y. Qian et al., "Evaluation of economic benefits of virtual power plant between demand and plant sides based on cooperative game theory," Energy Conversion and Management, vol. 238, 2021.

[43] H. Zhou, S. Fan, Q. Wu et al., "Stimulus-response control strategy based on autonomous decentralized system theory for exploitation of flexibility by virtual power plant," Applied Energy, vol. 285, 2021. 